\title{
Rethinking Optimum Currency Area Theory: Endogenous synchronisation of shocks in Europe
}

\author{
José Pedro Garcia*
}

January, 2017

\section{Nova School of Business \& Economics \\ School of Business and Economics, Maastricht University}

Master Thesis developed under the supervision of Professors Maria Eugénia Mata and Tom van Veen

\begin{abstract}
This work aims to assess whether the hypothesis of endogenous synchronisation of shocks is verified in the European Economic and Monetary Union (EMU). A state-space model, which yields time-varying coefficients, is estimated with structural demand and supply shocks to several European economies and those of Germany, which serves as a benchmark country. The goal is to understand to what extent have structural shocks to the German economy become more or less correlated with shocks to the other European economies throughout the EMU experience. The study is also applied to U.S. regions in order to have a useful standard of comparison. Even though the hypothesis of endogeneity cannot be unequivocally corroborated in Europe, I show that there is a large set of EMU member states whose demand shocks are becoming increasingly desynchronised with those of Germany. This may cast doubt on the prospects of a successful European monetary union as it is today. Moreover, amongst the key findings there is also proof that U.S. regions are a much more cohesive economic bloc than European countries.
\end{abstract}

Keywords: Optimum currency area theory; Endogenous; Monetary integration; Synchronisation of shocks

\footnotetext{
* This work benefited from several comments and suggestions, specially from Professors Maria Eugénia Mata and Tom van Veen, to whom I am deeply grateful. I am also thankful to Professor Francesco Franco, who kindly agreed to comment on my work. Last, but not least, my sincerest gratitude to my parents, siblings and closest friends, for all their unabated support and encouragement throughout this enterprise.
} 


\section{Introduction}

Since the European sovereign debt crisis has been triggered, both policy-makers and an increasing share of scholars brought optimum currency area theory (OCA hereafter) to the centre of debate. Though the question whether or not the European Economic and Monetary Union (EMU) is an optimum currency area has been answered negatively by a large majority of economists ${ }^{1}$, OCA can still be convenient to understand how the robustness of the EMU might be improved.

However, despite its usefulness, there have been significant criticisms to the appropriateness of OCA to yield detailed analyses of monetary unions. Firstly, according to Bordo and Jonung (1999), the theoretical framework set forth by it is somewhat static and ahistorical and, consequently, it does not allow to capture the features of the processes associated with the appearance and dissolution of monetary unions. Secondly, and more importantly, OCA is a mere ex-ante cost-and-benefit analysis of the suitability of a certain group of countries to form a monetary union. Following the argument put forward by Frankel and Rose $(1996,1997)$, as processes of monetary integration are dynamic ones, the criteria laid out by OCA may need to be taken as endogenous to the processes themselves.

Let us take the example of Portugal and Germany. If shocks to these two countries are negatively correlated and the assumption of sticky prices, sluggish labour movements and inexistence of a fiscal union holds, a well-informed and knowledgeable economist would certainly advise the Portuguese and German Governments not to engage in a monetary union: an autonomous monetary policy, which could be used as a means of stabilisation, would simply be too valuable to be forgone in those circumstances. Yet, Frankel and Rose drew attention to the fact that as a process of economic and monetary integration is fostered, linkages between the involved countries are strengthened - for instance, business cycles may become more correlated as countries increase their economic relations. Hence, even though Portugal and Germany do not fulfil the OCA criteria a priori, the process of economic and monetary integration may actually lead them to fulfil such criteria a posteriori, ergo the need to take the latter as endogenous.

The present dissertation aims to add to the existing literature by appropriately addressing these two sources of criticism. On the one hand, it seeks to study whether the assertion related to the endogeneity of OCA criteria is valid in the context of the EMU. More specifically, through the estimation of a state-space model, which allows for the existence of time-varying coefficients, I intend to assess to what extent have shocks to European economies become more or less correlated throughout the EMU experience, thus challenging the hypothesis of endogeneity of this specific criterion. Such shocks will firstly be obtained through a Structural Vector Autoregression (SVAR)

\footnotetext{
${ }^{1}$ See Eichengreen (1991), Bayoumi and Eichengreen (1992a, 1992b) and De Grauwe (2016).
} 
model with long-run restrictions, as suggested by Blanchard and Quah (1989). On the other, this research endeavour aspires to overcome the critique opportunely made by Bordo and Jonung (1999). In order to do so, I will employ the same econometric methodology to another monetary union, namely that of the U.S. ${ }^{2}$, so it may become possible to compare and to contextualise the results obtained for the European countries. A careful analysis of the institutional features of both the EMU and the U.S. monetary union will then have to be undertaken, so that the comparison between them does not come out as distortive.

The importance of this work is not just academic. Indeed, as European politicians are nowadays struggling to present the right agenda for the future of the EMU, the issue of endogeneity of OCA criteria might shed some light on it. If, for example, shocks to the several European economies are proven to evolve as country-specific as the process of integration is deepened, EMU will only be sustainable and worthful if European leaders are willing to initiate a path of reforms, either in labour market or in the use of fiscal policy, that allows countries to balance the loss of autonomous monetary and exchange rate policies. So, following the results obtained, I intend to suggest what are the most appropriate reforms and measures European policy-makers should adopt in order to improve the EMU's robustness, thus contributing to its success and sustainability.

The remainder of the thesis is then structured as follows. Chapter 2 reviews the underlying theoretical framework of OCA, as well as its empirical applications in the context of the EMU. Chapter 3 presents a literature review on the two main topics covered in the dissertation: the hypothesis regarding the endogeneity of OCA criteria and the study of correlation of shocks and business cycles. Chapter 4 describes both the econometric methodology employed and the dataset. Chapter 5 is dedicated to the presentation of the main results of this inquiry. Lastly, conclusions and final remarks will appear in Chapter 6.

\footnotetext{
2 The choice was based on two main criteria. Firstly, it seemed appropriate that only monetary unions that most resemble the EMU should be chosen. So, following the terminology applied by Bordo and Jonung (1999), since the EMU has evolved as a national monetary union - a single monetary authority common to all members of the union - it is only logical that the choice should fall on a national monetary union as well, like the U.S.. The second criterion was related to the availability of the data. Even though I have thought about expanding the study to Canadian provinces, I could not find the required quarterly data on Canada's regions (see Chapter 4). However, I acknowledge that an improvement upon this work of mine would be to expand the analysis to other monetary unions, so that other final remarks and comparisons could arise.
} 


\section{OCA: Theory and evidence in the EMU}

The study of optimum currency areas must be traced back to the pioneer work undertaken by Mundell (1961), McKinnon (1963) and Kenen (1969). They argued that a set of regions should adopt a common currency if savings in transaction costs outweigh the rise in adjustment costs or, in other words, when gains are larger than losses. Such gains usually arise from the fact that, as countries share the same currency, exchange rate fluctuations no longer cause trade disruptions. Therefore, economies that benefit most from the monetary integration process are the ones that are more economically related in terms of trade, since the elimination of exchange rate uncertainty is much more valued. On the other hand, losses emerge from the fact that, when entering a monetary union, countries are no longer entitled to have their own monetary and exchange rate policies. So, as countries forgo these economic instruments, their ability to deal with country-specific disturbances is weakened.

Following this argument, one can draw the conclusion that an optimum currency area can only be built if the loss of autonomy of monetary and exchange rate policies can be replaced by other economic instruments that are able to fulfil stabilisation purposes, thus minimising adjustment costs. To accurately illustrate the problem at hand, let us assume that a shock hits aggregate demand positively in Germany and negatively in Portugal. Had an optimum currency area been built between these two countries and such an asymmetric shock could be tackled with several instruments: fiscal transfers could be assigned to Portugal in order to boost its economy or, when facing increasing unemployment, Portuguese workers could easily seek job opportunities in Germany's growing labour market so that the excess demand for labour in Germany and the excess supply in Portugal could be smoothly erased, leading both economies to a new equilibrium.

Evidence, however, suggests that the EMU is far from an optimum currency area. Even though Kenen stated that in an optimum currency area "there must be sufficient occupational mobility to reabsorb the labour and capital idled by adverse disturbances" (Kenen 1969, p.50), Gáková and Dijkstra (2008) drew attention to the fact that only $0,14 \%$ of the working age population of the EU-27 moved to another country within the EU. More recently, Arpaia, Kiss, Palvolgyi and Turrini (2014) pointed out that, in 2013, nearly $4 \%$ of the working age population of the EU lived in a different EU country than that where they were born, while, for the sake of comparison, $30 \%$ of the U.S. working age population lived in a region different from their birth one. These figures unmistakably show that labour mobility in Europe is still very low and, therefore, they cast doubt on the ability of labour movements to function as a proper stabilisation instrument within the EMU. 
Interestingly, capital flows within the Eurozone displayed the opposite behaviour until the outbreak of the 2008 financial crisis $^{3}$. Indeed, Lane (2013) showed that capital flows amongst European countries amounted to $40 \%$ in 2007 , which could be seen as solid proof that financial markets at the European level were far more integrated than labour markets. Since then, despite the striking plunge of intra-euro-area capital flows that followed the financial turmoil of 2008 , the main point still holds: capital moves more easily within the EMU than labour. Nevertheless, in the light of OCA, such result must be taken cautiously. Even though free mobility of capital might be welfareenhancing, when coupled with sluggish labour movements, it may actually emphasize the effects of a negative shock. For instance, if Portugal had been negatively hit by the aforementioned countryspecific disturbance, not only would unemployment rise, as capital would also effortlessly flow out of the country in search for higher profitability. The Portuguese economy would then be required to undertake a much more demanding adjustment process in order to restore its full employment.

Given the existence of immobile labour, adjustments in productive factors can only be automatically sparked if prices and wages are easily adjusted. If wages were flexible, though Portuguese unemployed workers would not seize the increasing job opportunities in Germany, wage claims in Portugal would reduce. In Germany, on the other hand, the excess demand for labour would drive the wage rate up. While in the former case prices would decrease and Portuguese products would then become more competitive, the opposite would occur in the latter. So, if wages were flexible enough, those adjustments would allow to stimulate demand in Portugal and, therefore, to restore equilibrium. Yet, given the immobility of labour in Europe and the existence of sticky prices, adjustments in labour markets can only be achieved at the expense of unemployment, which brings about social and economic costs that must be taken into account.

In the absence of an effective and automatic adjustment carried out by productive factors, the use of fiscal policy might be the solution for Governments to tackle asymmetric shocks in a monetary union. Let us consider the effects of an asymmetric shock affecting Portugal and Germany when fiscal policy is driven at the national level. Intuitively, the negative demand shock in Portugal leads to an increasing deficit in the Portuguese public accounts, because tax revenues decline and unemployment benefits increase. Furthermore, in order to counterbalance the effects of the negative shock, the Portuguese Government can be lured to adopt an expansionary fiscal policy that has also a negative impact on its budget. However, as long as investors are willing to lend their funds to a Government who shares the same currency as trustworthy Germany, the use of a decentralised fiscal policy in a monetary union poses no problem. On the contrary, if public debt starts to increase rapidly, investors

\footnotetext{
${ }^{3}$ Following the literature on optimum currency area theory, capital flows are understood as movements of financial capital only.
} 
will require a higher interest rate to accommodate the increasing risk, making it difficult for the negatively hit countries to use sovereign fiscal policy as a means to stabilise the level of output.

Additionally, since international capital markets have recently shown not to be the best risksharing mechanism, Bordo, Jonung and Markiewicz (2013) claimed that a monetary union, such as the EMU, does require a system of interregional transfers which can smoothen the consequences induced by asymmetric shocks. According to Sala-i-Martin and Sachs (1991), such system of fiscal federalism can alleviate between one third and one half of a negative shock in the income per capita of a U.S. region. So, if an interregional system of payments had been put in practice, an European central authority would have automatically redistribute income from growing Germany to the depressed Portuguese economy, so that such transfers could partially offset the negative effects of the shock.

So far, European leaders have failed to take a step forward towards a higher degree of fiscal integration and since labour mobility is not sufficiently high to work as a stabilisation tool, countries within the EMU cannot cope with negative shocks properly. Following OCA, the conclusion that the EMU is not an optimum currency area arises almost inevitably. Nevertheless, though the sluggishness of labour movements amongst European countries and the inexistence of a fiscal union move the EMU away from being an optimum currency area, synchronisation of shocks and business cycles might work in an opposite way. According to Mundell's cost-and-benefit analysis, when economic structures of a set of countries are remarkably similar, such that their business cycles are fairly synchronised, severe adjustment costs will not be imposed because disturbances are almost the same and, therefore, a common monetary policy can be set in order to benefit all members simultaneously: one size fits all. However, when countries of a monetary union have their business cycles fully desynchronised - let us assume that all shocks that positively affect Germany's demand affect that of Portugal in a negative way and vice-versa - adjustment costs are considerably high, since a common monetary policy will either be beneficial to stabilise Germany's or Portugal's output, but not both at the same time.

As it has already been shown that Europe lacks a sufficiently high degree of labour mobility, coupled with the widely accepted proposition of price stickiness and the inexistence of a fiscal union, it seems reasonable to assume that both synchronisation of shocks and similarities amongst economic structures in European economies play a crucial role in assessing the costs associated with the EMU. Basically, when shocks that hit EMU countries are positively and significantly correlated, an European Central Bank can set a monetary policy that smoothens the effect of common shocks and adjustments costs are thereby minimised; conversely, if those disturbances are in fact country-specific and asymmetric, a common European monetary policy will be able to stabilise the business cycle in a specific country, but it will surely emphasize the effects of the shock in others. Thus, the extent to which shocks across the Eurozone are correlated and synchronised is an interesting way to evaluate the costs associated with the EMU, as well as the suitability of countries to be part of it. 


\section{Literature Review}

This third chapter surveys the existing literature on the subject of the present thesis. For the purpose of comprehension, two sections will be presented. While the first one concerns itself with the work that has already been done on the issue of the endogeneity of OCA criteria, the second one is related to the study of correlation of shocks and business cycles.

\subsection{The hypothesis of endogenous OCA criteria}

For some time now, economists have been relying on the work of Mundell (1961), McKinon (1963) and Kenen (1969) - the founding fathers of OCA - to assess whether a given group of countries should form a currency union. Following a cost-and-benefit setting, they all argued that countries should weigh benefits and costs associated with the entrance in the monetary union and, as long as the former are larger than the latter, such entrance would be profitable and, accordingly, advisable.

As the prospects of an European monetary union started to increase during the early nineties, several scholars have turned to this theoretical framework laid out by OCA to address the following questions: "is a European monetary union economically justified?", "if so, which countries are more likely to benefit the most?" A large empirical literature was then dedicated to measure gains and losses associated with the future EMU, so that economists could determine which European countries were more suitable to be part of such project. ${ }^{4}$

Nevertheless, despite their wide acceptance, these works were not free from controversy. In a seminal paper, Frankel and Rose (1996) pointed out that "the suitability of European countries for EMU cannot be judged on the basis of historical data since the structure of these economies is likely to change in the event of EMU" (Frankel and Rose 1996, p. 4). Briefly, following the Lucas critique, they acknowledged that a process of monetary integration tends to change the structure of economies and, consequently, the suitability of a country to be part of a monetary union can only be rightly assessed once the process of integration sparks its effects on the economic structure. This idea would later on be corroborated by Frankel and Rose (1997) and Artis (2002). Likewise, Weber (1990) had

\footnotetext{
${ }^{4}$ Bayoumi and Eichengreen (1996) provided an exhaustive and complete survey of the literature on the subject, as well as an agenda for research.

${ }^{5}$ See Lucas (1976). The Lucas critique was named after Robert Lucas' decisive contribution to macroeconomic policymaking. According to him, one should not expect to accurately predict the economic effects of a given policy based on historical data, because the adoption of the policy itself often leads people to act differently, thus distorting the econometric model that supports the analysis.
} 
already mentioned that, if the Lucas critique holds, the study of the former European Monetary System (EMS) would not offer accurate forecasts for a future European monetary union as one could expect.

The implications of this theory cannot be disregarded. Prior to the paradigm-shifting work of Frankel and Rose, scholars often used historical data to determine whether a group of countries should embark on a currency union. For instance, if shocks to Portugal and Germany, say, in the past twenty years had hardly been correlated, thus suggesting a majority of country-specific disturbances, OCA would yield that those two countries should not engage in a monetary integration process, ceteris paribus. However, what economists had failed to realise was that the monetary union itself could also impact on the correlation of shocks and business cycles, since higher integration influences trade and trade itself influences business cycles. Hence, the conclusion that OCA criteria should be taken as endogenous is easily drawn, since they evolve alongside the monetary integration process. On a similar note, De Grauwe (2013) stated that the major design failures embedded in the EMU were only perceived after they had exacerbated the effects of the financial crisis of 2008, because mainstream economic theory about optimum currency areas does not take the endogenous dynamics of capitalist economies into account. Ex-ante analyses are, for this reason, not the most appropriate ones, because a careful assessment of the suitability of a group of countries to be part of a monetary union should consider this issue of endogeneity, namely the effects that higher integration triggers on the correlation of shocks and business cycles.

Yet, in order to understand how the correlation of business cycles is likely to evolve in the event of a monetary union, one must study the sign of such relationship. Interestingly, two opposite views can be found in the literature. On the one hand, there is the so-called European view, named after the European Commission's (1990) report "One Market, One Money", crucial to the deepening of the integration process in Europe. In it, the EC claimed that the continuing economic and monetary integration in Europe would only make the involved countries more alike and, by extension, asymmetric shocks would become less important: "Economic integration will make the occurrence of country-specific shocks less likely since the product differentiation tends to dominate product specialization." (European Commission 1990, p. 136) .

The theory put forward by the EC can be summarised as follows. Firstly, as a monetary union would be built in Europe, trade amongst the involved countries would most certainly increase due to savings in transaction costs countries would gain from sharing a common currency. The main question, however, rests on the kind of trade that would likely to be created. If, for example, furthering integration would lead to inter-industry specialisation - countries exploit their comparative advantages and, therefore, each one of them specialises in a certain industry -, then a shock to a specific sector would asymmetrically affect the country in which the hit industry would be located. Conversely, if trade would tend to evolve according to an intra-industry specialisation pattern - countries exchange 
products belonging to the same industry -, when a specific sector would be hit by a shock, all countries would suffer from it. So, if the argument is clear, one should be able to understand that the occurrence of symmetric shocks is larger when deeper integration induces intra-industry trade. Curiously enough, this was the view backed by the EC (1990), who argued that, as intra-industry specialisation is characterised by the existence of economies of scale and product differentiation, the removal of barriers to the full exploitation of these advantages would increase intra-industry trade amongst European countries. Therefore, since the completion of the internal market was likely to render the effects of industry-specific shocks more symmetric across countries, the Commission was able to sustain the positive effects of monetary integration on the correlation of shocks and business cycles.

So far, several academics have been able to provide empirical support to this European view. Using both regional and national data on employment across several European countries, Fatás (1997) conclusively showed that the integration process that had been taking place in Europe from 1966 until 1992 did not favour specialisation at the country level. Moreover, through the estimation of a simple econometric model which related bilateral trade intensity and bilateral correlations of real economic activity between a set of developed countries, Frankel and Rose $(1996,1997)$ reported that trade linkage amongst two countries is strongly and significantly associated with more tightly correlated economic activity between them. The same conclusion was reached by Dées and Zorell (2011), who stated that GDP of economies with more intensive bilateral trade move more closely together.

Nevertheless, Krugman (1993) offered a second and remarkably different view on the issue. In his view, as a process of increasing integration is pushed forward, inter-industry trade increases and, therefore, country-specific shocks, which are asymmetric by definition, are more prone to occur. Following his argument, a reduction in transaction costs amongst regions "will make it more likely that any given degree of external economies will be sufficient to lead to geographical concentration of an industry" (Krugman 1993, p. 244) and, by extension, to a rise of inter-industry trade. Basically, Krugman argued that, due to furthering integration, the reduction of all sorts of transaction costs would only increase comparative advantage some countries already had over others in a specific industry. Hence, fostering European economic and monetary integration would lead countries to specialise in a particular sector, thus generating increasingly external benefits for firms in that location through knowledge spillovers, labour pooling, close proximity of specialised suppliers and economies of scale.

The specialisation pattern revealed by U.S. regions is, to this extent, an appropriate example to follow. For instance, following Krugman (1993), the New England region, and like others in the U.S., was extremely specialised. At the time, the export base of the region was concentrated in narrow high technology sectors, such as mini-computers, advanced medicine and precision military hardware, which tied New England's booms and slumps to the performance of those specific sectors. So, if this high degree of specialisation at the regional level was induced by the greater integration of the U.S. 
market, as suggested by Krugman, the process of deeper integration in Europe could not be expected to yield different results. Therefore, according to this line of thought, as the European monetary integration would evolve, specialisation at the country level would increase, as well as inter-industry trade and business cycles would become more idiosyncratic and asymmetric, thus jeopardising the sustainability of the future European currency area.

The main argument regarding the endogeneity of OCA criteria seems to be well-established in the literature: higher levels of integration do have an impact on the correlation of business cycles, since the former tends to boost trade amongst the involved countries. If trade evolves as inter-industry type, countries become more specialised in a given industry and their economies are then subject to be hit by asymmetric industry-specific shocks. Rather, if trade develops as intra-industry kind, countries exchange products of the same industry and, for that reason, sector-specific shocks affect all countries equally. If this is the case, countries are more likely to fulfil the criterion of symmetry of shocks for entry into a currency area ex-post, instead of ex-ante, as recognised by Frankel and Rose (1996, 1997).

\subsection{The correlation of business cycles in the context of OCA}

Following what has been previously buttressed, the correlation of business cycles is an interesting way to assess the costs countries bear when they enter a monetary union. The literature on this issue is comprehensively enough to include a wide range of empirical approaches to the problem. This should not come as a surprise, since by the time a European monetary union started to be regarded as a real possibility, economic researchers dedicated their endeavours to quantify both benefits and costs stemming from such an ambitious project. Although some authors have also made significant contributions in the fields of labour movements and fiscal federalism ${ }^{6}$, a larger share of scholars was leaned towards the analysis of correlation of shocks and business cycles across European countries.

Weber (1990) was, in this regard, one of the first works to be undertaken. His main goal was to empirically evaluate the asymmetries that had been revealed by the former EMS and their implications to a future European monetary union ${ }^{7}$. In order to accomplish what he had set up for his analysis, Weber assessed to what extent European countries that had participated in the EMS since its very

\footnotetext{
${ }^{6}$ On the issue of labour movements, Blanchard and Katz (1992) and Decressin and Fatás (1995) are usually taken as important benchmarks. On the other hand, Sala-i-Martin and Sachs (1991) and Bayoumi and Masson (1995) offered very indepth insights to a possible fiscal union in Europe.

${ }^{7}$ As mentioned earlier, Weber acknowledged the possible effects of the Lucas critique in the event of a future EMU. However, he only wanted to assess the performance of European countries throughout the EMS experience in order to draw possible implications for a future currency union in Europe. "(...) it is beyond the scope of this paper to make quantitative predictions about the effects of policies under the EMU as opposed to the present EMS system." (Weber 1990, p.5)
} 
beginning had their business cycles synchronised. Therefore, he measured the differentials between domestic demand and supply (proxied by the growth of retail sales volume indices and the growth of industrial production indices, respectively) and monetary base growth and real money growth across countries, as well as the variability of nominal and real exchange rates, inflation, nominal and real interest rates, real fiscal expenditure, real wages and unemployment and, finally, current account. Even though he found that some variables behaved quite symmetrically throughout the EMS experience - to wit, nominal and real exchange rates, nominal interest rates, inflation and current account -, some disturbing conclusions were still drawn. For instance, not only did he prove that both real wages and unemployment behaved in a significantly asymmetric way, thus suggesting the inexistence of a cohesive European labour market, as he also highlighted the asymmetric pattern across countries revealed by money supply and demand.

Following this work of Weber, many other scholars have employed different techniques on raw economic variables in search of correlation of business cycles across European countries. Beine and Hecq (1997) used co-dependence analysis on unemployment and short-run real interest rates, which allowed them to account for the existence of long-run relationships between those variables in European countries and those of Germany. De Grauwe (1996), on the other hand, drew attention to the real interest rate differentials across countries prior to their entrance in the EMU, whereas Eichengreen (1991) compared stock price differentials amongst Canadian and European regions in order to realise that region-specific shocks were greater in Europe than in Canada.

More recently, in their quest for betterment and accuracy, authors have changed both their measurement procedures as well as the kind of data employed. Wynne and Koo (2000), for instance, characterised the degree of synchronisation of business cycles amongst European countries and U.S. Federal Reserve districts in terms of the extent to which these cycles were correlated with each other. In order to do so, instead of just measuring differentials and standard deviations of the data as a proxy for their variability, they computed correlation coefficients of detrended data on output, employment and price level. The detrendig procedure used in the analysis was the band-pass (BP) filter, which allowed them to obtain cyclical components of those three variables. Amongst their key findings, they found empirical support to the idea that there is a considerably higher degree of correlation of business cycles in U.S. regions than in European countries: $40 \%$ of the pairwise correlations amongst European countries were not statistically significant, while for the U.S. Federal Reserve districts that same figure only amounted to $4,55 \%{ }^{8}$.

Despite being more econometrically sophisticated than other works that had already been done on the issue of correlation of business cycles, the study of Wynne and Koo was still not able to overcome

\footnotetext{
${ }^{8}$ Calculations of my own, based on Tables 1(a) and 2(a), pp. 352 and 359, respectively.
} 
important shortcomings. Indeed, from the point of view of faithfulness to Mundell's analysis, measuring the variability or the correlation of observed output movements, as it has been undertaken by Weber (1990) and Wynne and Koo (2000), did not allow to disentangle disturbances from responses. Let us think about Portugal and Germany, once more. Imagine that before they entered the EMU, both countries had been hit by an identical shock. Let us also consider the hypothesis that, for some reason, output in Germany was able to return to its initial level more rapidly than in Portugal. The correlation between German and Portuguese output is, therefore, quite low, even though both economies were hit by a perfectly symmetric shock. Hence, concerning OCA criterion of correlation of shocks only, the path revealed by output and other main economic indicators is hardly of any use.

The most well-known answer to this problem, and which is still regarded as a benchmark on the field of OCA criteria, was undertaken by Bayoumi and Eichengreen (1992a). Using data on output and prices spanning the period 1960-1988, and following the long-run restriction suggested by Blanchard and Quah (1989) that demand shocks have only a temporary effect on output, they estimated a SVAR and thus obtained structural supply and demand shocks to European countries and U.S. regions. Disturbances and responses were, this way, disentangled. So, by computing the correlation coefficient amongst countries' supply and demand shocks and those of Germany, they were able to acknowledge the existence of a core of European countries and a peripheral group. While the core was made up of Germany and its closest neighbours (France, Belgium, Luxembourg, the Netherlands and Denmark) due to the high correlation amongst supply and demand disturbances that affected these economies, the periphery gathered Portugal, Spain, Greece, Ireland, Italy and the U.K., whose supply and demand shocks were not sufficiently correlated with the ones that hit Germany ${ }^{9}$. Furthermore, they too drew the conclusion that shocks to European countries were more idiosyncratic than the ones affecting U.S. regions. The same analysis was later on expanded by Bayoumi and Eichengreen (1992b, 1994) in order to include a larger set of countries in the sample, but with remarkably similar conclusions.

The importance of these works is widely recognised, as well as their implications. On the one hand, they have encouraged many other scholars to pursue this line of empirical research. Funke (1996), for instance, recovered supply and demand shocks from an estimated SVAR on European countries and West Germany länders and computed the correlation coefficient amongst them. Not surprisingly, his results "overwhelmingly suggest that West Germany is, regionally, a good deal more equal than the EU and therefore a superior candidate for a monetary union (...)". (Funke 1996, p. 465) On the other, their results emphasized that the European monetary integration process ought to be taken cautiously by policy-makers, since a significant share of countries was proven not to be the most suitable to be part of a future EMU.

\footnotetext{
${ }^{9}$ Such distinction between European countries was later on operationalised in Bayoumi and Eichengreen (1997).
} 
Since then, most studies on the issue of correlation of shocks and business cycles across European economies have improved upon the pioneer work of Bayoumi and Eichengreen, but they have invariantly reached the same conclusions. Verhoef (2003) estimated the same SVAR model, but in lieu of computing correlation coefficients across countries' disturbances he used principal component analysis. Another interesting approach was presented by Chamie et al. (1994), who extracted three different kinds of structural shocks from the data: supply- and demand-side, though the latter were decomposed into real and nominal sources. Basically, instead of the bivariate SVAR put forward by Bayoumi and Eichengreen, they estimated a trivariate system using data on industrial production, the consumer price index and the M1 monetary aggregate in a set of European countries and U.S. regions. Finally, in order to decompose the previously identified structural disturbances into their unobservable symmetric and asymmetric components, they estimated a state-space model.

Given the scope and desideratum of the present dissertation, the use of an econometric methodology like the state-space model, which allows for the existence of time-varying coefficients, is certainly one of the most adequate ones. Indeed, if one intends to study the appropriateness of the hypothesis regarding the endogeneity of OCA criteria in the context of the EMU, one must have an approach that is likely to capture the specific features of the problem at hand. For instance, by computing correlation coefficients across structural shocks for a given time period, Bayoumi and Eichengreen implicitly assumed that symmetry of disturbances remains fairly constant, when, in fact, it may vary throughout time due to the hypothesis of endogeneity of OCA criteria. The process of economic and political integration in Europe is an evolutionary one, which is why the correlation of business cycles and symmetry of shock cannot be expected to be the same in the early-sixties as in the late-eighties. Therefore, a modelling approach which captures the dynamics of the process affecting the synchronisation of shocks amongst European countries is, I believe, a necessary improvement that must be made upon the work that has already been undertaken.

Hence, rather than computing static measures of correlation, as it was done in the seminal work of Bayoumi and Eichengreen, I will estimate a state-space model on the structural demand and supply shocks recovered from the raw data. So, I will purposefully estimate time-varying coefficients in order to understand the dynamics of synchronisation and convergence of shocks between European countries and those of Germany (the benchmark country) throughout the entire EMU experience. To my knowledge, the work that most resembles this of mine was undertaken by Boone (1997). Since then, the EMU was already built and put into practice and, consequently, his analysis can be expanded in order to investigate to what extent have shocks to European economies become more or less correlated throughout the EMU experience, thus properly challenging the hypothesis of endogeneity of OCA criterion regarding the correlation of shocks and business cycles. 


\section{Methodology}

The purposes of this chapter are twofold. On the one hand, it seeks to present the econometric methodology employed; on the other, it aims to provide a description of both the sources and properties of the data.

\subsection{Econometric methodology}

My point of departure to investigate the endogeneity of OCA criterion regarding the symmetry of shocks will be the seminal approach set forth by Bayoumi and Eichengreen (1992a, 1992b, 1994), which enabled them to disentangle shocks and disturbances from raw data.

I will firstly recover structural demand and supply shocks using a SVAR model, perfectly identified with the long-run restrictions suggested by Blanchard and Quah (1989). Such restrictions can be easily understood with the familiar aggregate demand and aggregate supply diagram: aggregate demand $(\mathrm{AD})$ curve is downward sloping in the output-price plane, whereas the short-run aggregate supply (SRAS) curve is upward sloping. The long-run supply (LRAS) curve, on the other hand, is vertical in the same plane, thus reflecting the existence of a level of output which ensures full employment. For the sake of argument, we can think of an initial situation where the economy is at its long-run equilibrium, which is given by the intersection point of these three curves.

Let us first consider that the economy is permanently hit by a positive demand shock - either an expansionary monetary or fiscal policy is adopted or exports suddenly increase, for instance. The adjustment process to this disturbance is depicted in Figure 1 of the Appendix. The initial AD curve moves to the right and a new macroeconomic equilibrium is attained at a higher level of output and prices. Nevertheless, due to the increase in prices, the SRAS curve gradually moves to the left, as firms have to bear increasingly higher wages. Therefore, in the long-run, the newly generated AD and SRAS curves meet at the initial level of output, which is determined by the vertical LRAS curve, but at a higher level of prices. Basically, while the immediate response to a permanent and positive shock to aggregate demand is an increase in both output and prices, in the long-run run output is kept unchanged at its initial value and only prices increase.

Let us now simulate the effects of a permanent and positive supply shock to the economy, namely a favourable technological discovery which allows a significant raise in productivity. Figure 2 of the Appendix graphically presents the adjustment process that follows. The immediate response is a rightward movement of both the SRAS and LRAS curves. So, in the long-run, the new equilibrium is 
reached at a higher level of output and lower prices. Hence, unlike demand shocks, supply-side ones have long-run effects on both output and prices.

The use of a SVAR model, which relies on the above mentioned identification of the shocks, clearly fits the main purpose of this thesis, because not only does it allow to study the dynamics of disturbances to European economies, as it is also an econometric methodology supported by economic reasoning ${ }^{\mathbf{1 0}}$. The econometric procedure is structured as follows. Firstly, let us consider a system where the true model of the economy can be represented by an infinite moving average representation of a vector of variables $\boldsymbol{X}_{\boldsymbol{t}}$ and an equal number of structural shocks $\boldsymbol{\mu}_{\boldsymbol{t}}$. Formally, using the lag operator $\boldsymbol{L}$, this can be written in the following way:

$$
\begin{aligned}
X_{t} & =\mathrm{K}+A_{0} \mu_{t}+A_{1} \mu_{t-1}+A_{2} \mu_{t-2}+A_{3} \mu_{t-3}+(\ldots) \\
& =\mathrm{K}+\sum_{i=0}^{\infty} L^{i} A_{i} \mu_{t}
\end{aligned}
$$

Vector $\boldsymbol{X}_{\boldsymbol{t}}$ comprises the first difference of natural logarithm of both real GDP $\left(\Delta y_{t}\right)$ and prices $\left(\Delta p_{t}\right)^{11}$. While $\Delta y_{t}$ can be seen as the real economic growth, $\Delta p_{t}$ yields the inflation rate of the economy. On the other hand, $\mathbf{K}$ is a matrix of constant terms, whereas the elements of matrices $\boldsymbol{A}_{\boldsymbol{i}}$ represent the impulse response functions of the structural shocks to the elements of vector $\boldsymbol{X}_{\boldsymbol{t}}$. Matrix $\boldsymbol{A}_{\mathbf{1}}$, for instance, comprises the responses in variables of vector $\boldsymbol{X}_{\boldsymbol{t}}$ to a shock in period $t-1$. Finally, vector $\boldsymbol{\mu}_{\boldsymbol{t}}$ comprises both demand $\left(\mu_{D_{t}}\right)$ and supply $\left(\mu_{S_{t}}\right)$ shocks, which are structural in the sense that they are uncorrelated at all leads and lags. Hence, the model of the economy can be given more specifically by the following representation:

$$
\begin{aligned}
& X_{t}=\mathrm{K}+\sum_{i=0}^{\infty} L^{i} A_{i} \mu_{t} \Leftrightarrow \\
& \Leftrightarrow\left[\begin{array}{l}
\Delta y_{t} \\
\Delta p_{t}
\end{array}\right]=\left[\begin{array}{l}
k_{11} \\
k_{21}
\end{array}\right]+\sum_{i=0}^{\infty} L^{i}\left[\begin{array}{ll}
a_{11_{i}} & a_{12_{i}} \\
a_{21_{i}} & a_{22_{i}}
\end{array}\right]\left[\begin{array}{l}
\mu_{D_{t}} \\
\mu_{S_{t}}
\end{array}\right]
\end{aligned}
$$

${ }^{10}$ The identification of the shocks is supported by economic theory, since from the AD-AS model one knows that demand shocks have only a temporary effect on output, whereas supply shocks have long-run effects on both output and prices. Yet, the use of a SVAR model also has its drawbacks. In one of the first critiques to the use of this estimation tool, Lippi and Reichlin (1993) pointed out that the VAR estimation procedure is based on arbitrary assumptions about the moving-average representation. However, it is far beyond the scope of this thesis to take it into proper account.

${ }^{11}$ Instead of using prices, Blanchard and Quah (1989) used unemployment to test their long-run restrictions. Personally, I find that using prices may be more intuitive, since the long-run restriction can be more easily understood in terms of economic theory. 
It is worth mentioning that, in the representation above, $a_{12}$ is the element in the first row and second column of matrix $\boldsymbol{A}_{\boldsymbol{i}}$. Furthermore, the premise that demand and supply disturbances are assumed to be uncorrelated can be more formally given by the assumption that their variance covariance matrix is diagonal, which, for the purpose of convenience, the literature often assumes to be the identity matrix: $\operatorname{Var}\left(\boldsymbol{\mu}_{\boldsymbol{t}}\right)=\boldsymbol{I}$. Lastly, according to the long-run restriction put forward by Blanchard and Quah (1989), demand-side shocks have only a temporary effect on output. However, since output in vector $\boldsymbol{X}_{\boldsymbol{t}}$ is written in first difference form, the restriction implies that the cumulative effect of demand shocks on the change of output be zero ${ }^{12}$, such that the following condition holds:

$$
\sum_{i=0}^{\infty} a_{11_{i}}=0
$$

The structural model described by equations (1.1) and (1.2) can be estimated by a Vector Autogression, where each element of $\boldsymbol{X}_{\boldsymbol{t}}$ is regressed in lagged values of all elements of the vector itself. Hence, the following bivariate system is left to be estimated by Ordinary Least Squares (OLS):

$$
\begin{aligned}
X_{t} & =D+B_{1} X_{t-1}+B_{2} X_{t-2}+(\ldots)+B_{n} X_{t-n}+\varepsilon_{t} \\
& =D+\sum_{i=1}^{n} L^{i} B_{i} X_{t}+\varepsilon_{t} \\
& =(I-B(L))^{-1}\left(D+\varepsilon_{t}\right) \\
& =\Lambda+\varepsilon_{t}+\Gamma_{1} \varepsilon_{t-1}+\Gamma_{2} \varepsilon_{t-2}+\Gamma_{3} \varepsilon_{t-3}+(\ldots)
\end{aligned}
$$

Equation (3) is then a Vector Autoregressive representation (VAR) of the dynamic structural model defined by both equations (1.1) and (1.2). Matrices $\boldsymbol{D}$ and $\boldsymbol{B}_{\boldsymbol{i}}$ comprise the estimated coefficients, whereas $\varepsilon_{\boldsymbol{t}}$ is a $2 \mathrm{x} 1$ matrix with the residuals obtained from each of the two equation of the system. Let us assume that $\varepsilon_{\boldsymbol{t}}=\left[\begin{array}{l}\varepsilon_{y_{t}} \\ \varepsilon_{p_{t}}\end{array}\right]$, where $\varepsilon_{y_{t}}$ is the residual from the first equation which has first difference of output as its dependent variable, while $\varepsilon_{p_{t}}$ stands for the residual of the second equation of the system which has first difference of prices as its dependent variable. The obtained residuals need not be uncorrelated between them, as they are a linear combination of all shocks affecting the economy. In fact, the estimated variance covariance matrix of $\boldsymbol{\varepsilon}_{\boldsymbol{t}}$ can be simply given by $\boldsymbol{\Omega}$, which is a non-diagonal matrix: $\operatorname{Var}\left(\boldsymbol{\varepsilon}_{\boldsymbol{t}}\right)=\mathbf{\Omega} \neq \boldsymbol{I}$.

\footnotetext{
${ }^{12}$ From the specification of the model, one is able to understand that the element $a_{11_{i}}$ - the upper-left entry (first row, first column) of matrix $\boldsymbol{A}_{\boldsymbol{i}}$ - yields the effect of a demand shock in $\Delta y$ after $i$ periods. So, following the same reasoning, $\sum_{i=0}^{k} a_{11_{i}}$ gives the effect of a demand shock in the actual level of $Y$ after $k$ periods. Therefore, if the restriction states that demand shocks have no long-run effects on the level of output, then $\sum_{i=0}^{\infty} a_{11_{i}}=0$.
} 
So far, the estimated VAR only allows to obtain the residuals associated with the two equations of the system, as well as their variance covariance matrix. So, those residuals $\boldsymbol{\varepsilon}_{\boldsymbol{t}}$ must be converted into structural demand and supply shocks. Equations (1.1) and (3) may provide the answer. Indeed, comparing those two equations, residuals and structural shocks can be related in the following way:

$$
A_{0} \mu_{t}=\varepsilon_{t} \Leftrightarrow \mu_{t}=A_{0}^{-1} \varepsilon_{t} \Leftrightarrow \mu_{t}=C \varepsilon_{t}
$$

The fact that $\boldsymbol{A}_{\mathbf{0}}^{\mathbf{- 1}}=\boldsymbol{C}$ is merely a convenient simplification. If the argument is hitherto clear, one should be aware that $\boldsymbol{\varepsilon}_{\boldsymbol{t}}$ and $\boldsymbol{\mu}_{\boldsymbol{t}}$ are both $2 \times 1$ matrices and, ergo, matrix $\boldsymbol{C}$ must comprise four elements. Hence, the main question rests on whether those four elements of $\boldsymbol{C}$ can be perfectly identified. If they can, then the estimation of the system's residuals is sufficient to recover the required structural shocks.

From equation (4), the following identity can be drawn:

$$
\operatorname{Var}\left(A_{0} \mu_{t}\right)=\operatorname{Var}\left(\varepsilon_{t}\right) \Leftrightarrow A_{0} A_{0}^{\prime}=\Omega
$$

$\boldsymbol{A}_{\mathbf{0}}^{\prime}$ is the transpose matrix of $\boldsymbol{A}_{\mathbf{0}}$. Matrix $\boldsymbol{\Omega}$, on the other hand, is the known variance covariance matrix of the residuals associated to equation (3). However, though matrix $\boldsymbol{A}_{\mathbf{0}}$ has four elements, matrix $\boldsymbol{\Omega}$ can only provide three different ones: the variance of both $\varepsilon_{y_{t}}$ and $\varepsilon_{p_{t}}$ and the covariance between them. A fourth and final restriction must be given by the long-run restriction that demand shocks have only a temporary effect on output, which requires that equation (2) be imposed. The argument ought to be examined cautiously. Firstly, equations (1.1) and (3) define that $A_{i}=\Gamma_{i} A_{0}$. From equation (2), however, one knows that the upper-left entry of $\sum_{i=0}^{\infty} A_{i}$ is zero, which formally gives the long-run restriction put forward by Blanchard and Quah (1989). So, the combination of these two last identities yields that the element in the first row and first column of $\left(\sum_{i=0}^{\infty} \Gamma_{i}\right) A_{0}$ must be zero. Since $\sum_{i=0}^{\infty} \Gamma_{i}$ is estimated by OLS, the required fourth restriction to perfectly identify matrix $A_{0}$ is thereby given. Ultimately, as $\boldsymbol{A}_{\mathbf{0}}$ is uniquely identified, so it is matrix $\boldsymbol{C}$ and, therefore, the estimation of the residuals is a sufficient condition to obtain the structural demand and supply shocks.

The recovery of those structural disturbances is, nevertheless, only the first step of the econometric methodology employed by the current thesis. Unlike Bayoumi and Eichengreen, who computed the correlation coefficient of demand and supply shocks between Germany and the other European economies, my analysis aims to embrace the dynamics features associated with the effects of furthering integration. Accordingly, since it allows for the existence of time-varying coefficients, the use of an econometric methodology like the state-space model is more likely to offer an increasingly accurate and dynamic measure of convergence of structural shocks across economies.

It is important to bear in mind that, even though the econometric methodology employed by the current thesis relies on the combination of a SVAR model with a state-space, these are independent 
from each other. Bayoumi and Eichengreen (1992a, 1992b), for instance, started their analysis with the demand and supply shocks recovered from a SVAR model, but they went on to compute correlations coefficients across them. The estimation of a state-space model is simply an improvement upon that work, since it offers a more dynamic measure of correlation between the shocks obtained from the same SVAR model, thus allowing to have a proper understanding about the hypothesis of endogenous OCA criteria.

The model can be given by the following equations:

$$
\begin{aligned}
& Y_{t}^{i}=\alpha_{t}+\beta_{t} Y_{t}^{j}+\xi_{t} \\
& \alpha_{t}=\alpha_{t-1}+\eta_{\alpha_{t}} \\
& \beta_{t}=\beta_{t-1}+\eta_{\beta_{t}}
\end{aligned}
$$

Equation (6) is labelled the measurement equation of the state-space model, while (7.1) and (7.2) are their transitions equations. In (6), $Y_{t}^{i}$ is a given variable $Y$ in country $i$ and period $t$, which is regressed in the same variable $Y$ in the same period $t$, but in country $j$. The last term of the equation $\xi_{t}$ - is a white-noise error term, whose mean is thus set equal to zero and its variance constant. On the other hand, $\alpha_{t}$ and $\beta_{t}$ are both time-varying coefficients, each one of them defined by an autogressive process of order one, as showed in (7.1) and (7.2), respectively. So, $\eta_{\alpha_{t}}$ and $\eta_{\beta_{t}}$ are also white-noise residuals - mean zero and constant variance - associated with each transition equation.

Despite its seemingly simplicity, the underlying estimation procedure of the state-space model is, in fact, rather complex. The estimation of the time-varying unobserved parameters of the model relies on the Kalman filter, which offers the maximum likelihood estimator for all $\alpha_{t}$ and $\beta_{t}$. A more detailed and thorough explanation regarding the procedure implemented by this estimation tool can be found in Appendix A of Boone (1997).

The economic and political implications drawn from this inquiry rely largely on the way the model has been built. So, in order to have an unclouded understanding of the subject matter, the following interpretation must be borne in mind. For the sake of illustration, let us assume that the measurement equation (6) is used to assess the dynamic correlation of supply shocks between Portugal and Germany, such that $Y_{t}^{i}=\mu_{S}{ }_{t}^{P T}$ and $Y_{t}^{j}=\mu_{S}{ }_{t}^{G E R}$, where $\mu_{S_{t}}^{P T}$ and $\mu_{S_{t}}^{G E R}$ stand for the earlier obtained structural supply shocks to Portugal and Germany, respectively, in period $t$.

According to the hypothesis of endogenous OCA criteria, once Portugal and Germany have entered the EMU, the correlation between their shocks would change, which implies an evolution of parameter $\beta$ throughout time. Intuitively, if parameter $\beta$ remains fairly constant during the time period 
which spans the EMU experience, the hypothesis regarding the endogeneity of this specific OCA criterion cannot be accepted ${ }^{13}$. However, if $\beta$ does change, several interpretations can be made in the light of the economic theories that have been previously set forth. If parameter $\beta$ tends to decrease, supply shocks to Germany become either increasingly insignificant explain supply shocks to Portugal - in the case when there is only a movement towards 0 - or fully desynchronised with the latter. One way or another, Krugman's negative view on the effects that deeper integration triggers on the correlation of shocks and business cycles cannot be rejected and, therefore, the prospects for a sustainable and well-succeeded European currency area cannot be grounded in empirical research.

A more optimistic viewpoint on the effects sparked by furthering integration in Europe can only be attained if $\beta$ actually presents a positive trend. If this is the case, when $\beta$ starts to increase as time goes by, supply shocks to Germany become progressively more significant to explain supply shocks to Portugal and, thus, the so-called European view finds empirical support not to be rejected.

Although the study focuses on the evolution of $\beta$, parameter $\alpha$ can be simply interpreted as a measure of exogenous synchronisation, which embodies other possible sources of convergence aside from the chosen benchmark country.

Given the importance of the evolution of parameter $\beta$ to the conclusions regarding the hypothesis of endogeneity of OCA criteria, another econometric approach will be implemented in order to accurately assess whether $\beta$ has been increasing, decreasing or remaining constant throughout time. So, once the state-space model is estimated and the evolution of $\beta$ obtained, I will estimate by OLS the following linear equation:

$$
\beta_{t}=\theta_{0}+\theta_{1} t+\omega_{t}
$$

Equation (8) posits that the earlier obtained parameter $\beta_{t}$ is regressed in a constant term $\theta_{0}$, in a trend variable $t$ and in a white-noise error term $\omega_{t}$. The trend variable $t$ is defined as $t=$ $1,2,3,4, \ldots, n$, where the first period of the samples takes the value 1 , the second period takes the value 2 , until the $n$-th period takes the value $n$.

\footnotetext{
${ }^{13}$ If an optimistic point of view on the effects of the European integration process is accepted a priori, one would suggest that parameter $\beta$ should increase over time. However, the hypothesis of endogeneity only requires a change of the parameter, it does not specify whether it increases or decreases. The European view would say that increases, while Krugman would forecast a decrease. Nevertheless, since my first job is to prove the hypothesis of endogeneity, I can only say that $\beta$ is likely to change. Afterwards, if the hypothesis is indeed proven, I shall assess who is right: either the European Commission or Krugman.
} 
If the coefficient $\theta_{1}$ which is associated to this trend variable is not statistically significant, then $\beta_{t}$ is assumed to have remained fairly constant at a level of $\theta_{0}$ throughout the analysed time period. The hypothesis of endogeneity of the criterion regarding the correlation of shocks can then be rejected. Yet, if $\theta_{1}$ is in fact statistically significant, one must conclude for the existence of a certain evolution of parameter $\beta$ and, by extension, for the validity of the hypothesis of endogenous OCA criteria. Moreover, if this is the case, the European's view will not be rejected if $\theta_{1}>0$ : parameter $\beta$ has a positive and upward trend and, therefore, structural supply shocks to Germany are increasingly prone to explain structural supply shocks to Portugal. Conversely, when $\theta_{1}$ is both significant and lower than 0 , Krugman's more pessimistic view on the effects of integration cannot be rejected due to the existence of a downward trend of parameter $\beta .^{14}$

This interpretive reasoning can be applied to the study of convergence of both demand and supply shocks. All that is left to do is to define a benchmark country $j$. Here, I will once again follow the work of Bayoumi and Eichengreen (1992a, 1992b) and choose Germany as a benchmark for the EMU and the region of Mid-East for the U.S. ${ }^{15}$. The results will of course be subject, not only to the choice of those benchmarks, but also to the framework laid out by the estimated state-space model. Nevertheless, I strongly believe this specification is the one that allows to properly study the problem at hand: the introduction of time-varying parameters, instead of static measures of correlation, allows to have a better understanding about the endogeneity of symmetry of shocks, while the structure of the model determines whether those disturbances tend to become more positively or negatively correlated.

\subsection{Data}

Given the scope of the thesis, measures of real economic growth and inflation had to be collected for European countries and U.S. regions. However, in order to duly address the main purpose of the current dissertation, several important issues regarding the data have to be kept in mind.

Firstly, it is my intention to have a comprehensive set of European countries, so that the hypothesis regarding the endogeneity of OCA criterion can be assessed with as much carefulness as

\footnotetext{
${ }^{14}$ Even though this is a simple and intuitive technique, it also has its drawbacks. Above all, when assessing the evolution of parameter $\beta$ through a trend variable, as defined in equation (8), I am not concerned with possible structural breaks. In other words, I implicitly assume that coefficient $\theta_{1}$ is always the same. Synchronisation of shocks might have happened at a much higher pace during the first years of the EMU, which would be translated into a steeper upward trend. However, since synchronisation cannot increase unlimitedly, the slope of an upward trend variable would inevitably have to decrease. Yet, the gains stemming from such straightforward econometric technique can outweigh this shortcoming.

${ }^{15}$ As the largest economy of the EMU, Germany has played an important role on the design of the economic and institutional features of the currency area, making itself the most obvious candidate for a standard of comparison. The MidEast comprises the most important economic and financial centres of the U.S.: New York and District of Columbia.
} 
possible. Thus, to analyse the evolution of shocks in Europe, I gathered data from the OECD Quarterly National Accounts for fifteen out of the nineteen EMU participants (Austria, Belgium, Estonia, Finland, France, Germany, Greece, Ireland, Italy, Latvia, the Netherlands, Portugal, Slovakia, Slovenia and Spain), for a set of European countries which could be taken as a control group (Denmark, Sweden, Switzerland and the United Kingdom) and, finally, for the Euro Area as a whole ${ }^{\mathbf{1 6}}$. Second, the selected time period should comprise the entire EMU experience, but also some years prior to its creation. Furthermore, in order to enrich the study with as many observations as possible, quarterly data were chosen over annual. The time period ranging between 1997q1 and 2015q4 was the one that, not only was available for all the twenty countries that have been selected, but also allowed to comply with the two restrictions I had imposed beforehand. Lastly, since vector $\boldsymbol{X}_{\boldsymbol{t}}$ comprises measures of real economic growth and inflation, the OECD Quarterly National Accounts provided data for the seasonally adjusted real GDP and GDP deflator ${ }^{17}$. So, as stated earlier, for each country real economic growth and inflation were measured by the first difference of the natural logarithm of real GDP and GDP deflator, respectively. This procedure also ensures that the two variables that are fed into vector $\boldsymbol{X}_{\boldsymbol{t}}$ are stationary. The results of the tests which account for the existence of a unit-root in those series are reported in the following chapter.

Before analysing the results obtained from the use of the data, it might be useful to consider it prior to any econometric transformation. To that extent, Table 1 provides the correlation coefficients of real economic growth and inflation between each European country and Germany in both the full period covered by the sample and the period after the country's entrance in the EMU.

Interestingly, correlations between real economic growth are clearly more significant than correlations between inflation. Regarding the former, the results do prove the existence of a core of European countries in the sense of Bayoumi and Eichengreen (1992a, 1992b). Indeed, after their entrance in the EMU, countries whose real economic growth follows more closely that of Germany are essentially its neighbours (Austria, Belgium, France and the Netherlands), but also Finland, Italy, Slovakia and Slovenia. Likewise, Switzerland presents a high correlation coefficient as well, though it does not belong to the EMU. Furthermore, Table 1 also reveals the importance of Germany in the

${ }^{16}$ Only Cyprus, Luxembourg, Malta and Lithuania were left out. Though the OECD database provides data for Luxembourg, there were none spanning the entire chosen time period. Cyprus, Malta and Lithuania, on the other hand, do not belong to the OECD and, consequently, it was not possible to collect the required data from the same source. Nevertheless, not only are these four countries relatively insignificant in the context of the EMU, as the selected group of countries already seems to be reasonably large and diverse. One can also easily realise that the chosen countries have not entered the EMU simultaneously. This is actually a strength of this work and does not pose a problem. Firstly, despite the year of entrance in the monetary union, shocks can still be recovered for the entire period. Secondly, when the state-space model will be estimated, it will be curious to have different years of entrance. Estonia and Latvia have entered the EMU quite recently, for instance. Is there already a process of convergence of shocks to Germany taking place?

${ }^{17}$ Following the terminology employed by the used data source, real GDP and GDP deflator are labelled series LNBQRSA and DOBSA, respectively. 
entire Euro Area economy, as the correlation coefficient between their real economic growth is nearly 0.88 - the highest value in the entire table.

Table 1: Correlations between real economic growth and inflation of European countries and those of Germany

\begin{tabular}{lcccc}
\hline \hline & \multicolumn{2}{c}{ Correlation of real growth to } & Correlation of inflation to Germany \\
\hline & Full period & After entrance in & Full period & After entrance in \\
& $1997-2015$ & EMU & $1997-2015$ & EMU \\
Austria & $0.6558^{*}$ & $0.6792^{*}$ & 0.1733 & 0.1032 \\
Belgium & $0.6197^{*}$ & $0.6128^{*}$ & -0.1721 & -0.2161 \\
Denmark & $0.4349^{*}$ & & -0.1067 & \\
Estonia & $0.4633^{*}$ & 0.2261 & $-0.3158^{*}$ & -0.4362 \\
Euro Area & $0.8762^{*}$ & & $0.3416^{*}$ & \\
Finland & $0.6692^{*}$ & $0.7111^{*}$ & 0.1079 & 0.2151 \\
France & $0.7181^{*}$ & $0.7446^{*}$ & -0.1813 & $-0.3725^{*}$ \\
Greece & $0.2931^{*}$ & 0.2190 & 0.1313 & 0.2127 \\
Ireland & 0.1287 & 0.0745 & -0.1205 & -0.0662 \\
Italy & $0.7081^{*}$ & $0.7337^{*}$ & 0.0315 & 0.0491 \\
Latvia & $0.3448^{*}$ & 0.3202 & -0.0881 & -0.2214 \\
the Netherlands & $0.6775^{*}$ & $0.7071^{*}$ & -0.1756 & -0.1562 \\
Portugal & $0.4106^{*}$ & $0.4233^{*}$ & $-0.2686^{*}$ & -0.2261 \\
Slovakia & $0.4261^{*}$ & $0.8838^{*}$ & $-0.2530^{*}$ & -0.0637 \\
Slovenia & $0.6115^{*}$ & $0.7728^{*}$ & -0.1866 & 0.0144 \\
Spain & $0.4111^{*}$ & $0.4085^{*}$ & -0.1807 & -0.2249 \\
Sweden & $0.5535^{*}$ & & 0.1039 & \\
Switzerland & $0.6277^{*}$ & & $-0.2761^{*}$ & \\
United Kingdom & $0.6000^{*}$ & & -0.1628 & \\
\hline \hline & & & & \\
\hline
\end{tabular}

Notes: Austria, Belgium, Finland, France, Ireland, Italy, the Netherlands, Portugal and Spain entered the EMU in 1999; Greece in 2001; Slovenia in 2007; Slovakia in 2009; Estonia in 2011; Latvia in 2014; Denmark, Sweden, Switzerland and the United Kingdom are not part of the EMU.

Asterisk (*) denotes statistical significance of the coefficients at a 5\% level.

It is worth mentioning that no important conclusions regarding the endogeneity of OCA criteria can be drawn from Table 1. On the one hand, the latter presents static measures of correlations, as I have called them earlier, which do not fully capture the dynamic features of the economic and monetary integration process. On the other hand, given the analysed time period, for most countries there is hardly any difference between correlation for the full period and correlations for the period 
after the entrance in the EMU. So, the main purpose of Table 1 is to merely illustrate interesting properties of the collected European data.

Finally, since the current thesis also intends to focus on the U.S. monetary union, similar data had to be gathered for American regions. To my knowledge, the Bureau of Economic Analysis (BEA) is the most accurate data source to do so. Therefore, I used BEA Regional Accounts to obtain quarterly data on nominal and real GDP spanning the period 2005q1-2015q4 for the eight standard regions of the U.S. defined by the BEA itself: Far West, Great Lakes, Mid-East, New England, Plains, Rocky Mountains, Southeast and Southwest. I also collected the same data for the United States as a whole. The recovery of demand and supply shocks requires that both a measure of real economic growth and inflation be used. Nevertheless, since a measure of prices is not directly given by BEA to the eight regions, I used nominal and real GDP to compute the implicit GDP deflator and, then, wrote the former and the latter in the first difference of their natural logarithm in order to put them in vector $\boldsymbol{X}_{\boldsymbol{t}}$. This procedure is exactly the same as the one that has been applied to European data and allows to ensure stationarity of the variables, which can be corroborated by the unit-root tests presented in the following chapter.

Table 2: Correlations between real economic growth and inflation of U.S. regions and those of the Mid-East

\begin{tabular}{lcc}
\hline \hline & $\begin{array}{c}\text { Correlation of real growth to } \\
\text { the Mid-East } \\
\text { Full period }\end{array}$ & $\begin{array}{c}\text { Correlation of inflation to the } \\
\text { Mid-East }\end{array}$ \\
& $2005-2015$ & Full period \\
& $0.3011^{*}$ & $2005-2015$ \\
Far West & $0.5345^{*}$ & $0.7254^{*}$ \\
Great Lakes & $0.5459^{*}$ & $0.8934^{*}$ \\
New England & $0.4021^{*}$ & $0.9272^{*}$ \\
Plains & -0.0412 & $0.6733^{*}$ \\
Rocky Mountains & $0.4100^{*}$ & -0.0370 \\
Southeast & -0.0431 & $0.8743^{*}$ \\
Southwest & $0.5746^{*}$ & -0.1404 \\
United States & & $0.6160^{*}$ \\
\hline \hline
\end{tabular}

Note: Asterisk $(*)$ denotes statistical significance of the coefficients at a 5\% level.

Following the analysis made to the European dataset, Table 2 reports the correlation coefficients between each region's real economic growth and inflation and those of the Mid-East. These figures indicate that only Rocky Mountains and the Southwest are not significantly correlated with the MidEast, neither on real economic growth nor inflation. Furthermore, Table 2 also shows that, unlike the 
European case where correlations between inflation are lower when compared to those regarding real economic growth, U.S. regions are highly correlated in terms of inflation. Once again, only Rocky Mountains and the Southwest reveal a relatively idiosyncratic behaviour, which presumably arises from their specific patterns of production (clearly dominated by oil industries in the Southwest and by other raw material industries, agriculture and forestry in the Rocky Mountains states).

Nevertheless, the most striking property offered by the Table concerns the relationship between the benchmark region and the United States as a whole. From Table 1, one certainly recalls that the highest correlation coefficient to Germany was presented by the Euro Area, which could be read as a signal of the enormous importance of the former in the European economy. In Table 2, however, correlations between the Mid-East and the entire United States are not as high as those amongst Germany and the Euro Area. Even though it is possible to infer that the Mid-East does have a crucial role to play in the American economy, the difference between this particular region and the others is not that sharp, which prevents the existence of a core and peripheral groups. So, figures from Tables 1 and 2 show that both real economic growth and inflation are generally more correlated across U.S. regions than European countries, as the former are much more alike amongst them than the latter. 


\section{Main results}

This chapter presents the main results that stem from this study. Section 5.1 describes all the steps I have gone through in order to recover structural demand and supply shocks. Sections 5.2 and 5.3 describe the results arising from the estimated state-space model and whether these point to the existence of an evolutionary process of (de)synchronisation of demand and supply shocks. Section 5.4 discusses policy implications that can be drawn for Europe in the light of the results obtained.

\subsection{Demand and supply shocks}

The first step of the econometric methodology employed required that demand- and supply-side shocks, as identified by Blanchard and Quah (1989), were recovered from the data. In order to do so, the data on real GDP and GDP deflator for European countries and U.S. regions were written in first difference of their natural logarithm, thus becoming stationary variables that could be interpreted as real economic growth and inflation, respectively. To check that these series were truly stationary in all countries and regions, I performed both the Augmented Dickey-Fuller and the Phillips-Perron tests. The MacKinnon p-values are presented in Table 3 of the Appendix.

I defined, as a rule, that a given variable would only be taken as stationary if the null hypothesis that yields the existence of a unit-root could be rejected at a 5\% level in at least one of the two tests. Accordingly, Spain is the only country in the entire dataset whose real economic growth and inflation are not stationary.

To tackle the issue of non-stationarity of Spanish data, I started by running the Chow multiple breakpoint test for each variable: for real economic growth, the test suggests the existence of a structural break in 2008q3 and another one in 2011q2; for inflation, on the other hand, the test points to the existence of a first break in 2000q3 and a second one in 2008q2. Figure 3 (see Appendix) depicts the evolution of real economic growth and inflation in Spain, as well as the identification of these breaks. Aside from the first break underlying the series on inflation, all other breaks seem to be related to the economic and financial turmoil triggered by the 2008 crisis. Hence, in order to take these breaks into account, the VAR of the dynamic structural model of the Spanish economy also includes an exogenous dummy variable. Such dummy variable takes the value 1 between 2008q2 and 2011q2 and 0 otherwise, thus adding an additional source of explanation to the evolution of real economic growth and inflation during a period of financial and economic turbulence. 
To obtain the demand and supply shocks for all countries and regions, the VAR for each country and region was estimated with a uniform lag of four periods (quarters), such that equation (3) (see chapter 4) becomes:

$$
X_{t}=D+B_{1} X_{t-1}+B_{2} X_{t-2}+B_{3} X_{t-3}+B_{4} X_{t-4}+\varepsilon_{t}
$$

This procedure of setting the same lag of the VAR for all countries and regions aims to avoid any possible source of disturbance in the results across them. Yet, this choice can be properly justified both theoretically and empirically. Firstly, it is reasonable to assume that current real economic growth and inflation depend on their evolution over the past year. So, since I am dealing with quarterly data, the VAR was estimated with a lag of four quarters. I am aware, however, that one could argue that real economic growth and inflation depend rather on their evolution over the past two years for instance and, therefore, a lag of eight quarters should have been chosen. Nevertheless, following both the Akaike's and the Schwarz' Bayesian information criteria, the optimum lag criteria ranged between 0 and 6 for the European countries, while for the U.S. regions they ranged between 0 and 3 . The values for these criteria can be found in Table 4 of the Appendix and, coupled with the use of quarterly data, allow to justify the choice over a uniform lag of four quarters.

Before obtaining the structural demand and supply shocks, different robustness tests were performed to ensure the reliability of the estimation results of the VAR. The first one aimed to assess whether the residuals of the two equations of the system were normally distributed and, to do so, I ran the Jarque-Bera test, whose associated p-values can be found in Table 5 of the Appendix. The results for the European countries were, however, remarkably poor, since in only six out of twenty countries the residuals from the two equations from the VAR followed in fact a normal distribution (Belgium, Denmark, Greece, Italy, Portugal and Spain, as reported in the first column of the above mentioned Table). For the U.S. regions, on the other hand, only the residuals from the Far West revealed the same result.

The result presented by the European countries often points to the existence of outliers that correspond to one-off, extraordinary economic events that hit different countries, when the VAR may be of little use to explain the evolution of the economy in that period ${ }^{\mathbf{1 8}}$. So, the main question is whether these outliers reflect exogenous events which are common to most European countries, or whether they are essentially idiosyncratic shocks that cannot be explained by the model. If the first hypothesis is to be preferred, the common extraordinary event may be the turmoil that followed the 2008 financial crisis, since the evolution of real economic growth shows a plunge in literally all

\footnotetext{
18 It can also happen that the number of lags imposed is insufficient to yield satisfactory results. Nevertheless, the choice of setting the number of lags equal to four can be duly justified by Akaike's and Schwarz Bayesian's information criteria presented in Table 4, which allows to arguably rule this possibility out.
} 
European countries in the aftermath of the fall of Lehman Brothers. I used two different approaches to isolate this effect: firstly, I estimated the same VAR for all European countries for the period 19972007; secondly, I included a dummy as an exogenous variable in the VAR, which takes the value 1 between $2008 \mathrm{q} 4$ and $2009 \mathrm{q} 1$ and 0 otherwise ${ }^{19}$. These two procedures were not applied to the U.S. regions, because, aside from the single exception of the Far West, the initial results were already strong enough.

The results from these two approaches are reported in the second and third columns of Table 5, respectively, and do show that, once the immediate effects of the financial crisis are taken into account, a larger share of European countries starts to have normally distributed residuals. Nevertheless, these results must be cautiously analysed. Even though it improves the quality of the results, the first approach deletes eight years of data. Therefore, this improvement that is obtained might not be due to the fact that the financial crisis of 2008 is no longer included, but the fact that country-specific and unexplained shocks occurred mainly as of 2008. This statement can actually be reinforced by the results of the second approach. With the inclusion of the dummy variable which filters the effects felt in the subsequent quarters to the financial crisis, nine out of twenty countries still have non-normally distributed residuals. So, I could not find empirical support to claim that the results of the Jarque-Bera test for the European countries were fully generated by the common one-off event which was the turbulence triggered by the financial crisis of 2008. Furthermore, since the data do not point to the existence of another possible extraordinary event that could impact all European countries equally, the poor quality of the results must reflect a majority of specific and significant disturbances affecting most countries after 2008.

Given the fact that these two approaches were also unable to offer reasonable results with respect to the normal distribution of estimated residuals, demand and supply shocks were recovered from the initial VAR without the dummy variable for the effects of the 2008 financial crisis and using a time period ranging between 1997 and 2015. Yet, in the light of these results, the appropriateness of this model will be further discussed in the following chapter.

The final robustness test required the performance of the Breusch-Godfrey test for serial correlation of the residuals, also known as the LM test. Indeed, one of the so-called classical assumptions of the OLS estimation method imposes that residuals must be uncorrelated at all lags.

\footnotetext{
19 The dummy variable was included in order to filter the immediate economic effects sparked by the financial crisis of 2008. This was made after a careful analysis of the evolution of real economic growth in European countries. Despite the fact that the actual length of the recession may vary from country to country, this is the choice that best suits the data and, therefore, the best point of departure to expunge the short-run effects of such an exogenous event.
} 
Then, in the bivariate model which was built, the hypothesis requires the following: $\operatorname{Cov}\left(\varepsilon_{y_{t-i}}, \varepsilon_{y_{t-j}}\right)=\operatorname{Cov}\left(\varepsilon_{p_{t-i}}, \varepsilon_{p_{t-j}}\right)=0, \forall i \neq j$

Basically, this means that the residuals from both equations of the VAR must be serially uncorrelated: past residuals of real economic growth cannot influence future values of these, and the same applies to past residuals of inflation. It is important to highlight that this assumption differs from another similar one that has been previously laid out. In chapter 4, I stated that demand and supply shocks should be uncorrelated at all leads and lags, such that their variance covariance matrix would be the identity: $\operatorname{Var}\left(\boldsymbol{\mu}_{\boldsymbol{t}}\right)=\boldsymbol{I}$. More specifically, this means that demand shocks have no ability to explain the evolution of supply-side shocks, and vice-versa, because there is no correlation amongst them. On the other hand, I claimed that residuals associated to the two estimated equations could be correlated, as they are a linear combination of all shocks affecting the evolution of real economic growth and inflation. Their variance covariance matrix was then defined as a non-diagonal one: $\operatorname{Var}\left(\boldsymbol{\varepsilon}_{\boldsymbol{t}}\right)=\boldsymbol{\Omega} \neq \boldsymbol{I}$. In other words, this means that $\operatorname{Cov}\left(\varepsilon_{y_{t-i}}, \varepsilon_{p_{t-j}}\right) \neq 0, \forall i, j$. Given this explanation, one can understand the difference amongst all these assumptions, as well as the hypothesis of no serial correlation of the residuals hereby challenged by the LM test.

In order to have a better understanding of the subject matter, the LM test requires that the residuals from both equations of the VAR representation defined by equation (8) should be estimated by OLS through the following equation:

$$
\varepsilon_{y_{t}}=\alpha_{0}+\gamma_{i} \sum_{i=1}^{4} \Delta y_{t-i}+\varphi_{i} \sum_{i=1}^{4} \Delta p_{t-i}+\rho_{j} \sum_{j=1}^{n} \varepsilon_{y_{t-j}}+v_{t}
$$

Equation (9) states that the OLS residuals of the first equation of the VAR, which has real economic growth as its dependent variable, are regressed in a constant term $\alpha_{0}$, in the independent variables $\sum_{i=1}^{4} \Delta y_{t-i}$ and $\sum_{i=1}^{4} \Delta p_{t-i}$ which are part of equation (9) that has previously generated them, in $n$-lags of the residuals themselves and in a white-noise error term $v_{t}$. The same equation can then be applied to the residuals from the second equation of the VAR, which has inflation as its dependent variable.

Ultimately, the test requires that a maximum number of lags $n$ be chosen. I defined that the test should look for the existence of autocorrelation of residuals up to a lag of eight quarters. My goal was then to investigate whether the residuals from the two estimated equations were influenced by the residuals from the past eight quarters. If all eight parameters $\rho_{j}$ would prove to be statistically insignificant, then the hypothesis that yields the existence of autocorrelation between residuals could be rejected. 
The results that were obtained generally point to the absence of autocorrelation of the residuals associated to European countries and U.S. regions. Yet, Table 6 of the Appendix indicates all lags that had an estimated coefficient $\rho_{j}$ statistically different from zero, ergo suggesting the existence of autocorrelation $^{20}$. The most apparently troubling results are the ones that stem from Finland, Italy and Spain, where there are three significant lags. Nevertheless, as a rule of thumb, econometricians often conclude for the existence of autocorrelation when more than half of the lags is statistically significant. Since this is not the case for any European country or U.S. region, the results from the LM test can be seen as proof that there is no autocorrelation amongst residuals of the VAR, thus ensuring the appropriateness of the model.

After the two robustness tests were performed and the quality of the estimated VAR was duly ensured, I finally recovered structural demand and supply shocks for all countries and regions included in the dataset. Since it would be clearly unpractical to plot the evolution of these shocks for all countries and regions, I decided to only present a graphical comparison between the Euro Area and the United States and their chosen benchmarks - Germany and the Mid-East, respectively -, so that the importance of these two anchor regions could be assessed. These two comparisons are depicted in figures 4 and 5. Nevertheless, Table 6 yields the correlation coefficients between structural demand and supply shocks between all European countries and those of Germany, as well as for U.S. regions and the Mid-East. ${ }^{21}$


Figure 4 - Structural Demand (left) and Supply (right) Shocks in Germany and the Euro Area

\footnotetext{
${ }^{20}$ To run the LM test implies that $243 \rho_{j}$ coefficients be estimated (twenty European countries plus nine regions of the U.S., each one of them with eight parameters). Therefore, since it would be impossible to have a single table with all those pvalues, I am only reproducing the (few) ones that were statistically significant.

${ }^{21}$ I am still convinced that the computation of correlation coefficients between the shocks, as done by Bayoumi and Eichengreen (1992a, 1992b, 1994), is not the most appropriate way to draw significant conclusions regarding the similarity of business cycles. The presentation of such data (static measures of convergence, as I called them earlier) has merely illustrative purposes.
} 

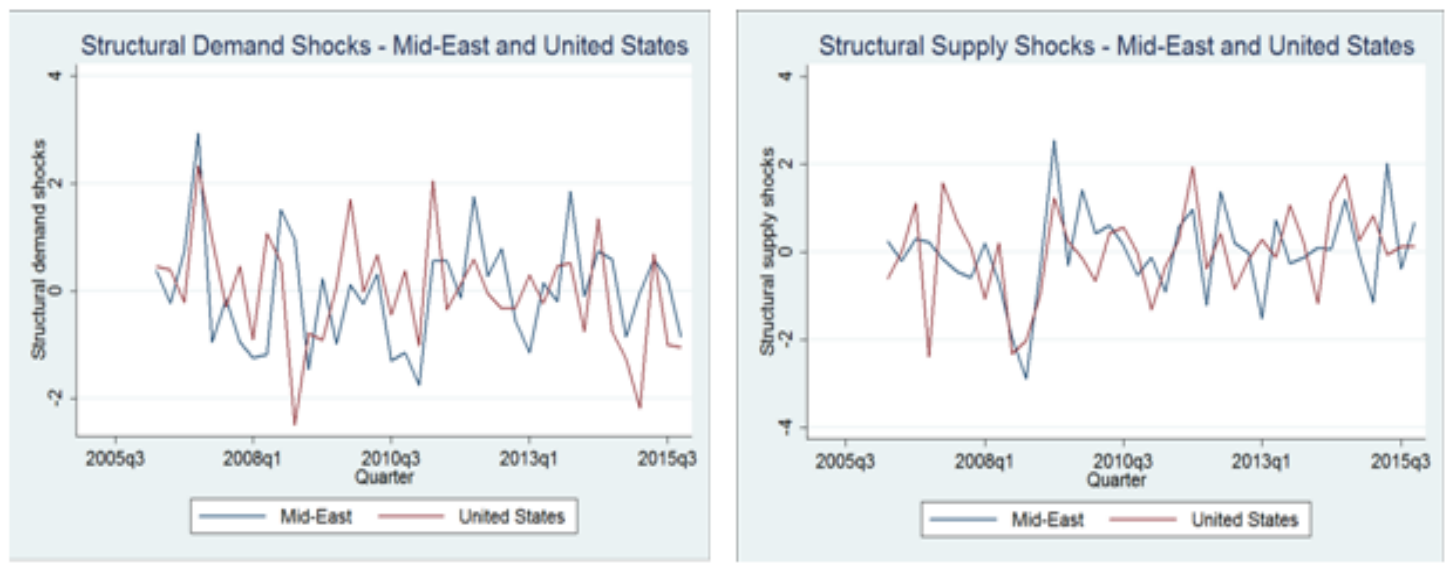

Figure 5 - Structural Demand (left) and Supply (right) Shocks in the Mid-East and the United States

In the European case, the most interesting feature is given by the right panel of Figure 4, which shows a positive and very close relationship between German structural supply shocks and those of the Euro Area. Following what has been previously posited with the analysis of Table 1, the data do reinforce the importance of Germany in the European economy: not only is real economic growth in Germany and the Euro Area highly correlated, as supply-side shocks of the former seem to co-move with the same shocks of the latter. The correlation coefficient presented between them is in fact the highest in the entire Table 6: 0.8558. As for demand shocks, left panel of Figure 4 shows that, even though disturbances to the Euro Area economy often follow the same direction as those to Germany, the magnitude of the shocks is different. The correlation between structural demand shocks of Germany and those of the Euro Area is lower than the one associated to structural supply shocks: 0.4496 , in spite of being statistically significant at a 5\% level, according to Table 6 .

Figure 5 plots the same evolution of structural shocks, but with respect to the United States and their chosen benchmark region: the Mid-East. Once again, the data prove that this region is not as important to the United States as Germany is to the Euro Area. The argument can be made clearer if the right panels of both Figures 4 and 5 are taken into account. Indeed, while supply shocks to the Euro Area economy appear to evolve tied to German supply shocks, the direction and magnitude of supply shocks to the American economy are not always the same as those of the shocks to the MidEast. In fact, the correlation coefficient between supply shocks to the United States as a whole and to the Mid-East, though statistically significant, is only 0.4085. Curiously, as in the European case, the relationship between demand shocks of the U.S. and those of its benchmark region is much weaker than the one defined by supply shocks. In fact, the correlation coefficient is not even statistically significant $(0.3117)$. 
Table 6: Correlations between structural demand and supply shock of European countries and U.S. regions

\begin{tabular}{|c|c|c|}
\hline & $\begin{array}{l}\text { Correlation of structural } \\
\text { demand shocks }\end{array}$ & $\begin{array}{l}\text { Correlation of structural } \\
\text { supply shocks }\end{array}$ \\
\hline Austria $^{+}$ & 0.1491 & $0.5422 *$ \\
\hline Belgium $^{+}$ & 0.0130 & $0.2736^{*}$ \\
\hline Denmark $^{+}$ & -0.0802 & 0.0875 \\
\hline Estonia $^{+}$ & -0.0697 & $0.4295^{*}$ \\
\hline Euro Area $^{+}$ & $0.4496^{*}$ & $0.8558^{*}$ \\
\hline Finland $^{+}$ & 0.1635 & $0.4356^{*}$ \\
\hline France $^{+}$ & -0.0421 & $0.3514 *$ \\
\hline Greece $^{+}$ & $0.2982 *$ & $0.3613^{*}$ \\
\hline Ireland $^{+}$ & 0.0535 & 0.0328 \\
\hline Italy $^{+}$ & -0.0334 & $0.5618^{*}$ \\
\hline Latvia $^{+}$ & 0.1279 & -0.1108 \\
\hline the Netherlands ${ }^{+}$ & -0.0994 & $0.5429 *$ \\
\hline Portugal $^{+}$ & -0.1730 & 0.1343 \\
\hline Slovakia $^{+}$ & -0.0833 & $0.3477 *$ \\
\hline Slovenia $^{+}$ & 0.0260 & $0.5546^{*}$ \\
\hline Spain $^{+}$ & -0.0377 & $0.2563^{*}$ \\
\hline Sweden ${ }^{+}$ & 0.0673 & $0.3550^{*}$ \\
\hline Switzerland $^{+}$ & -0.0831 & $0.3829 *$ \\
\hline United Kingdom $^{+}$ & -0.1434 & $0.3638^{*}$ \\
\hline Far West ${ }^{\mathrm{x}}$ & $0.5392 *$ & 0.2910 \\
\hline Great Lakes ${ }^{x}$ & $0.7519^{*}$ & $0.5624^{*}$ \\
\hline New England ${ }^{\mathrm{x}}$ & $0.6677^{*}$ & $0.4710^{*}$ \\
\hline Plains ${ }^{x}$ & $0.3247^{*}$ & $0.3162 *$ \\
\hline Rocky Mountains ${ }^{x}$ & -0.1094 & 0.2199 \\
\hline Southeast ${ }^{\mathrm{x}}$ & $0.5454^{*}$ & $0.3947 *$ \\
\hline Southwest ${ }^{\mathrm{x}}$ & $-0.3386^{*}$ & 0.0141 \\
\hline United States ${ }^{\mathrm{x}}$ & 0.3117 & $0.4085^{*}$ \\
\hline
\end{tabular}

Notes: Asterisk (*) denotes statistical significance of the coefficients at a $5 \%$ level.

${ }^{+}$Correlations to Germany

${ }^{x}$ Correlations to the Mid-East

If one recalls the theoretical background supporting the identification of these two kinds of disturbances, one will certainly recall that while demand shocks were labelled as temporary shocks to the level of output, supply-side shocks were taken as permanent disturbances to the economy. Following the examples that have been laid out, a demand shock can be seen as the adoption of an 
expansionary monetary or fiscal policy, whose positive effects on the level of output are only felt in the short-run, whereas a supply shock may be a favourable technological discovery which allows a significant raise in productivity. Hence, this distinction allows to claim that demand shocks are more policy driven than supply-side ones. In other words, this means that the former are more sensitive to policy choices than the latter ${ }^{22}$.

If the argument is clear, then the results displayed by Table 6 should come as no surprise. Indeed, given the fact that demand shocks tend to reflect different policy choices and since fiscal policy in Europe is decided at the national level, demand shocks are barely correlated. Put differently, even though the nineteen national fiscal authorities members of the EMU are bounded by the Stability and Growth Pact criteria, fiscal policies can be set independently by each one of them and, therefore, there cannot be a common European demand shock, nor can demand shocks to the German economy have a systematic impact on the economies of its peers. On the other hand, insofar as U.S. regions have also to submit to policies decided by a Federal Government, they may experience similar fiscal shocks ${ }^{23}$. The fact that the correlation of demand disturbances to American regions is higher and consistently more significant than the analogous correlations for European countries can then be properly justified.

As for supply shocks, since they are not mainly driven by policies, they are more prone to reflect exogenous disturbances that affect all economically similar countries and regions at the same time. Therefore, the fact that supply shocks are much more correlated than demand-side ones is an expected outcome, since despite their differences at the level of policy preferences, European countries and U.S. regions still have structural resemblances amongst them. To that extent, it is worth noting that two out of the three U.S. regions whose supply shock are not statistically correlated with those of the Mid-East are the Rocky Mountains and the Southwest, precisely those which have a more idiosyncratic behaviour in terms of real economic growth due to their specific production structures.

A complete study on the subject of endogeneity of OCA criteria must, however, take these two kinds of shocks into account, as they reflect different sources of disturbances to the economy. So, the following two sections present the results associated to the evolution of parameter $\beta$ of the state-space model in all European countries and U.S. regions for both demand and supply shocks.

\footnotetext{
${ }^{22}$ This does not mean that policy-makers are unable to promote permanent changes in the economy, such as a sustained increase in the level of productivity. Surely there are several policies that can achieve such goal. However, my main point is that productivity does not respond immediately to the adoption of a given policy, since it takes some time for structural changes to produce their desired effects. Output, on the other hand, may respond more quickly to an increase in public spending, for instance.

${ }^{23}$ Monetary policy is also a source of demand-side disturbances. Yet, the main difference between European countries and U.S. regions lies at the level of fiscal policy, since in both cases monetary policy is set by a common and single monetary authority: the ECB and the Fed, respectively. So, monetary policy was purposefully left out of this point I am making.
} 


\subsection{Dynamic correlation of demand shocks}

One of the main purposes of this dissertation is to add to the existing literature a more dynamic measure of correlation of shocks between countries. The state-space model defined by equations (6), (7.1) and (7.2) is, to that extent, a helpful tool, because it allows to estimate time-varying coefficients that better embrace the dynamic feature of the hypothesis of endogenous OCA criteria under analysis. Therefore, the main conclusions this study can draw regarding the latter rely largely on the evolution of parameter $\beta$ of the state-space model.

This section aims to present the results regarding the evolution of $\beta$ that quantifies the synchronisation of demand shocks between European countries and Germany on the one hand, and U.S. regions and those of the Mid-East on the other. It is worth recalling the econometric methodology upon which the following results have arisen: demand shocks were firstly recovered from a SVAR model and, afterwards, used as a dependent variable of the measurement equation of a state-space model, whose estimation allows to obtain $\beta$. In order to accurately assess its evolution, $\beta$ was ultimately regressed in a trend variable (see equation (9)). Ultimately, the validity of the hypothesis of endogenous OCA criteria depends on the existence of a statistically significant evolution of parameter $\beta$ throughout time. In other words, the main issue under analysis in the current thesis comes down to the question whether coefficient $\theta_{1}$ of equation (9) is statistically significant. If so, the European Commission's and Krugman's views will not be rejected as long as $\theta_{1}>0$ or $\theta_{1}<0$, respectively. In order to ease comprehension, Table 7 summarises all possible results that may arise from the test of statistical significance of coefficient $\theta_{1}$, as well as the implications attached to each one of them with respect to the hypothesis of endogeneity.

Table 7: Summary of possible results for the test of statistical significance of $\theta_{1}$

\begin{tabular}{|c|c|c|c|c|c|}
\hline \multicolumn{3}{|c|}{ European dataset } & \multicolumn{3}{|c|}{ American dataset } \\
\hline Hypothesis & Not rejected if ... & $\begin{array}{l}\text { Conclusion if not } \\
\text { rejected }\end{array}$ & Hypothesis & Not rejected if ... & $\begin{array}{l}\text { Conclusion if not } \\
\text { rejected }\end{array}$ \\
\hline $\mathrm{H}_{0}: \theta_{1}=0$ & $\mid$ t-Statistic $\mid<1.99$ & $\begin{array}{l}\text { No endogeneity of } \\
\text { shocks }\end{array}$ & $\mathrm{H}_{0}: \theta_{1}=0$ & $\mid$ t-Statistic $\mid<2.021$ & $\begin{array}{l}\text { No endogeneity of } \\
\text { shocks }\end{array}$ \\
\hline $\mathrm{H}_{1}: \theta_{1}>0$ & $\mathrm{t}-$ Statistic $>1.99$ & European view & $\mathrm{H}_{1:} \theta_{1}>0$ & $\mathrm{t}-$ Statistic $>2.021$ & European view \\
\hline $\mathrm{H}_{1}: \theta_{1}<0$ & t-Statistic $<-1.99$ & Krugman's view & $\mathrm{H}_{1:} \theta_{1}<0$ & $\mathrm{t}-$ Statistic $<-2.021$ & Krugman's view \\
\hline
\end{tabular}


The values of the test for statistical significance follow a $t$ distribution with $n-k$ degrees of freedom, where $n$ stands for the number of observations included (76 for the European dataset and 44 for the American one) and $k$ the number of independent variables included in equation (9) that allows the test to be run ( 2 variables in both cases). So, the values of the test for the European countries follow a $t$ distribution with 74 degrees of freedom, whereas the values for U.S. regions follow a $t$ distribution with 42 degrees of freedom. Therefore, using the critical values of the $t$ distribution for a significance level of $5 \%$, one can arrive at the critical values yielded by the Table above ${ }^{24}$.

Table 8 presents the results that stem from the test of statistical significance of coefficient $\theta_{1}$ for all European countries and U.S. regions, when the latter assesses the evolution of $\beta$ as a dynamic measure of correlation of demand shocks. For the sake of comprehension, European countries were divided into four groups following the distinction firstly put forward by Bayoumi and Eichengreen (1992a): a core of Northern and Central Europe countries which essentially comprises Germany's closest neighbours (Austria, Belgium, Finland, France and the Netherlands); a peripheral group of Southern Europe countries (Greece, Italy, Portugal and Spain) plus Ireland; a group of recently-entrant countries from Eastern Europe (Estonia, Latvia, Slovakia and Slovenia); and, finally, a group of EMUoutsiders (Denmark, Sweden, Switzerland and the United Kingdom). It should be noted that this distinction, even though it stems from the seminal work of Bayoumi and Eichengreen, it is slightly different from theirs, because it aims to reveal the current political and economic balance in Europe ${ }^{25}$.

The most striking conclusion one can draw from Table 8 is that the hypothesis of endogenous synchronisation of demand disturbances in Europe is not solidly confirmed. In nine out of the nineteen $(47,4 \%)$ European countries, the hypothesis of endogeneity is rejected. Furthermore, it is worth stating that the group of European countries for which the hypothesis is rejected (Austria, Denmark, Finland, Italy, Latvia, Portugal, Slovenia and Switzerland, besides the Euro Area as a whole) is reasonably diverse and, therefore, does not have any particular or common feature that can help to justify this result. In the U.S., on the other hand, the hypothesis of endogeneity is rejected in three out of eight regions (Great Lakes, Plains and the Southwest). So, even though the hypothesis is rejected in 37,5\% of the cases, one still cannot claim that evidence unmistakably points to its validity.

\footnotetext{
${ }^{24}$ The critical values of the $t$ distribution presented in Table 7 were taken from the following table, which can be accessed freely: http://www.sjsu.edu/faculty/gerstman/StatPrimer/t-table.pdf. The latter was last consulted in November, $14^{\text {th }}$. It is worth stating that the table does not yield the critical values of the distribution for 74 and 42 degrees of freedom. So, with no loss of generality, these two were approximated to 80 and 40 , respectively.

${ }^{25}$ Denmark, for instance, is now left out of the group of core economies, since I included another one which gathers EMU outsiders. Furthermore, by the time Bayoumi and Eichengreen had their work published (1992), Finland was only taken as a control country for being part of EFTA. Nowadays, the country seems to belong to the group of core countries due to the economic resemblances between German and Finnish economies.
} 
Table 8: Dynamic correlation of demand shocks

\begin{tabular}{|c|c|c|c|}
\hline & t-Statistic & P-value & Conclusion \\
\hline \multicolumn{4}{|l|}{ Core } \\
\hline Austria & 1.291266 & 0.2006 & No endogeneity \\
\hline Belgium & -8.128886 & $0.0000 *$ & Krugman's view \\
\hline Finland & -1.440984 & 0.1538 & No endogeneity \\
\hline France & -2.703653 & $0.0085^{*}$ & Krugman's view \\
\hline the Netherlands & -5.365418 & $0.0000 *$ & Krugman's view \\
\hline \multicolumn{4}{|l|}{ Periphery } \\
\hline Greece & -3.117974 & $0.0026^{*}$ & Krugman's view \\
\hline Ireland & -3.928843 & $0.0002 *$ & Krugman's view \\
\hline Italy & -0.133431 & 0.8942 & No endogeneity \\
\hline Portugal & -0.165515 & 0.8690 & No endogeneity \\
\hline Spain & -9.709483 & $0.0000 *$ & Krugman's view \\
\hline \multicolumn{4}{|c|}{ Recently-entrants } \\
\hline Estonia & 3.295178 & $0.0015^{*}$ & European view \\
\hline Latvia & -0.019855 & 0.9842 & No endogeneity \\
\hline Slovakia & -2.907968 & $0.0048 *$ & Krugman's view \\
\hline Slovenia & -1.029057 & 0.3068 & No endogeneity \\
\hline \multicolumn{4}{|c|}{ EMU-outsiders } \\
\hline Denmark & -0.799850 & 0.4264 & No endogeneity \\
\hline Sweden & 5.650125 & $0.0000 *$ & European view \\
\hline Switzerland & -1.329486 & 0.1878 & No endogeneity \\
\hline United Kingdom & 6.528986 & $0.0000 *$ & European view \\
\hline \multicolumn{4}{|l|}{ Euro Area } \\
\hline Euro Area & -0.509982 & 0.6116 & No endogeneity \\
\hline Far West & 2.313231 & $0.0257 *$ & European view \\
\hline Great Lakes & 1.365725 & 0.1793 & No endogeneity \\
\hline New England & -4.458695 & $0.0001 *$ & Krugman's view \\
\hline Plains & 0.390142 & 0.6984 & No endogeneity \\
\hline Rocky Mountains & -2.195862 & $0.0337 *$ & Krugman's view \\
\hline Southeast & 2.491011 & $0.0168 *$ & European view \\
\hline Southwest & 2.014596 & 0.0504 & No endogeneity \\
\hline United States & 4.284693 & $0.0001 *$ & European view \\
\hline
\end{tabular}

Note: Asterisk (*) denotes statistical significance of coefficient $\theta_{1}$ at a $5 \%$ level.

The results for the European countries also show another interesting result. For the remaining ten countries where the hypothesis of endogeneity of shocks cannot be rejected, there is clearly a 
predominance of Krugman's view. In fact, the only three countries where such view is rejected, suggesting instead the more optimistic European perspective, are Estonia, Sweden and the United Kingdom: these last two are not even part of the EMU, while the former is one of its most recent members. Basically, this means that for a large set of countries which are part of the EMU since its beginning (Belgium, France, Greece, Ireland, the Netherlands and Spain besides recently-entrant Slovakia), the results indicate that demand shocks have become more desynchronised with those of Germany. This means that the correlation between them has decreased through the EMU experience. It is worth mentioning that this specific group comprises most of Germany's closest neighbours.

Hence, since demand disturbances are mainly policy-induced ones, this result arises either from an increasing desynchronisation of fiscal policies decided at the national level or due to the inability of monetary policy set by the European Central Bank to affect all economies equally. Yet, another argument can be made in the light of Krugman's reasoning. Indeed, if demand-side shocks to these group of European economies has become more desynchronised with those of Germany, one can claim that the monetary union promotes inter-industry trade amongst a core of Central and Southern Europe countries $^{26}$. Let us assume that due to the monetary and economic integration process most of obstacles to intra-European trade are removed and, therefore, through economies of scale and knowledge spillovers, Germany's and Ireland's comparative advantages in the production of vehicles and pharmaceuticals products, respectively, are highlighted. If this is the case, a fall in the consumption of cars will have a negative impact on the German economy, but it will leave the Irish pharmaceutical-specialised economy unaffected. So, the increasing desynchronisation of demand shocks revealed by this particular group of countries may be explained by the fact that shocks to specific industries have been increasing over the past years.

Briefly, the results that were obtained for European economies show that, aside from the nine countries where convergence of shocks has remained constant, there does not seem to be a path of convergence of demand shocks to a large set of European countries and those to the German economy. Given the fact that EMU member states have their ability to deal with asymmetric disturbances constrained, as it was shown in Chapter 2, the increasing desynchronisation of shocks revealed by a significant set of countries casts doubt on the prospects of a sustainable European monetary union.

As for the remaining five U.S. regions where the hypothesis of endogeneity cannot be rejected, there is an increasing synchronisation of demand shocks with those of the Mid-East in three of them (Far West, Southeast and the United States as a whole) and a divergence of shocks in only two (New England and the Rocky Mountains). Like in the European case, there are not obvious and immediate

\footnotetext{
${ }^{26}$ In this particular case only, I am using the term "core" to define the group of Northern, Central and Southern Europe countries that is part of the EMU since its first years. It does not have the meaning coined by Bayoumi and Eichengreen (1992a), nor the distinction I have made previously.
} 
economic resemblances amongst the regions that comprise each of these two groups, which leaves this result unjustified. Nevertheless, while demand shocks to the Euro Area as a whole have not become either more or less correlated with those of Germany, there has been an increasing convergence between the same kind of disturbances to the Mid-East and the entire United States. This result actually reinforces the appropriateness of choosing the Mid-East as the benchmark region of the U.S., since data reveal that demand shocks to the region are more prone to explain demand shocks to the overall American economy.

\subsection{Dynamic correlation of supply shocks}

The study of convergence of supply shocks between European countries, on the one hand, and U.S. regions, on the other, is subject to the same methodological framework which was used to understand the evolution of the synchronisation of demand shocks. Therefore, the summary of possible results given by Table 7 applies as well. Table 9 yields the outcomes of the test of statistical significance of coefficient $\theta_{1}$, when the latter measures the evolution of $\beta$ as a dynamic measure of correlation of supply shocks.

Once again, the results for the European countries do not indicate that the hypothesis of endogeneity of disturbances can be unequivocally confirmed. In eight out of the nineteen countries, the hypothesis is rejected (Austria, Estonia, Euro Area, Greece, the Netherlands, Portugal, Slovenia and the United Kingdom). I can conclude that there is no general synchronisation of supply shocks to European economies to those of Germany, since in nearly $42 \%$ of the cases the correlation remains the same over time. Interestingly, this is what happens to the relationship between the entire Euro Area and Germany. Figure 4 and Table 6 have previously revealed that supply shocks to these two economies have always been positively and highly correlated. The results now yielded by Table 9 also show that this correlation has not been increasing nor decreasing, but it has remained the same throughout the period under analysis.

For the remaining eleven European countries where the hypothesis of endogenous correlation of supply shocks could be rejected, the optimistic European view tends to dominate. Indeed, supply shocks have become more synchronised with those of Germany in seven countries (Belgium, Finland, Italy, Slovakia, Spain, Sweden and Switzerland), while supply shocks to the other four economies (Denmark, France, Ireland and Latvia) have diverged from the ones to the German economy. Curiously, this result is different from the one obtained for the endogenous correlation of demand-side shocks, where Krugman's view dominated amongst countries for which the hypothesis of endogeneity could not be rejected. 
Table 9: Dynamic correlation of supply shocks

\begin{tabular}{|c|c|c|c|}
\hline & t-Statistic & P-value & Conclusion \\
\hline \multicolumn{4}{|l|}{ Core } \\
\hline Austria & 0.550068 & 0.5839 & No endogeneity \\
\hline Belgium & 3.222978 & $0.0019 *$ & European view \\
\hline Finland & 6.137583 & $0.0000 *$ & European view \\
\hline France & -5.313209 & $0.0000 *$ & Krugman's view \\
\hline the Netherlands & -1.393620 & 0.1676 & No endogeneity \\
\hline \multicolumn{4}{|l|}{ Periphery } \\
\hline Greece & 1.759110 & 0.0827 & No endogeneity \\
\hline Ireland & -9.597802 & $0.0000 *$ & Krugman's view \\
\hline Italy & 3.042495 & $0.0032 *$ & European view \\
\hline Portugal & 0.653477 & 0.5155 & No endogeneity \\
\hline Spain & 4.187599 & $0.0001 *$ & European view \\
\hline \multicolumn{4}{|c|}{ Recently-entrants } \\
\hline Estonia & 0.927077 & 0.3569 & No endogeneity \\
\hline Latvia & -4.208695 & $0.0001 *$ & Krugman's view \\
\hline Slovakia & 6.374813 & $0.0000 *$ & European view \\
\hline Slovenia & 1.141648 & 0.2573 & No endogeneity \\
\hline \multicolumn{4}{|c|}{ EMU-outsiders } \\
\hline Denmark & -2.156201 & $0.0343^{*}$ & Krugman's view \\
\hline Sweden & 7.632267 & $0.0000 *$ & European view \\
\hline Switzerland & 6.406385 & $0.0000 *$ & European view \\
\hline United Kingdom & -0.784122 & 0.4355 & No endogeneity \\
\hline \multicolumn{4}{|l|}{ Euro Area } \\
\hline Euro Area & -0.262884 & 0.7934 & No endogeneity \\
\hline Far West & 10.92840 & $0.0000 *$ & European view \\
\hline Great Lakes & -0.430848 & 0.6688 & No endogeneity \\
\hline New England & -5.941852 & $0.0000 *$ & Krugman's view \\
\hline Plains & -8.604351 & $0.0000^{*}$ & Krugman's view \\
\hline Rocky Mountains & 8.554798 & $0.0000^{*}$ & European view \\
\hline Southeast & 2.137797 & $0.0384 *$ & European view \\
\hline Southwest & 4.269776 & $0.0001 *$ & European view \\
\hline United States & 4.520999 & $0.0000 *$ & European view \\
\hline
\end{tabular}

Note: Asterisk (*) denotes statistical significance of the coefficient at a 5\% level.

By construction, supply-side shocks are supposed to reveal more permanent disturbances that affect economically similar countries in a fairly equal way. To that extent, one should indeed expect 
that supply shocks to EMU countries ought to become increasingly synchronised. Strikingly, despite the existence of a predominance of European view, the results that have been found show that this only happens to five EMU member states - Belgium, Finland, Italy and Spain plus recently-entrant Slovakia. It is worth recalling that the study of synchronisation of demand shocks showed that there is only one EMU country (Estonia) whose demand-side disturbances are in fact converging to those of Germany. Thus, both these results cast doubt on the positive effects triggered by the European monetary process at the level of correlation of shocks and business cycles.

The results associated to the study of synchronisation of supply shocks in Europe are more baffling from the ones arising from the evolution of demand shocks, since there is no clear trend about what the results suggest. Aside from the already mentioned conclusion that the thesis of endogeneity cannot be strongly advocated, the results only seem to indicate that some of the positive effects the EC expected to be triggered by the monetary integration process have still not occurred.

On the other hand, the results for the U.S. regions present a much clearer pattern. Firstly, out of the eight regions, the hypothesis of endogeneity is only rejected once (12,5\%): Great Lakes. As for the remaining seven regions, Krugman's view is not rejected in only two (New England and Plains). So, the study of convergence of supply-side shocks across U.S. regions does show that there is a majority of regions whose supply disturbances tend to become more synchronised with those of the Mid-East (Far West, Rocky Mountains, Southeast, Southwest and the United States as a whole). This means that the view that the EC laid out about the positive effects sparked by economic and monetary integration processes on the correlation of shocks finds empirical support, not in Europe, but in the U.S..

Interestingly, this result applies even to regions as Rocky Mountains and the Southwest, whose production structures and economic performance are not that much alike the ones presented by their peers. Moreover, following a result already obtained in the previous section, one must highlight the increasing synchronisation between supply shock to the Mid-East and to the entire American economy. Even though the correlation between supply shocks is not as high as the one between Germany and the Euro Area, the data suggest that supply shocks to the Mid-East are increasingly prone to explain supply shock to the United States as a whole, thus reinforcing the appropriateness of choosing the former as a benchmark region.

The difference amongst the results for European countries and U.S. regions should not be taken surprisingly. Indeed, the fact that there is a general movement of synchronisation of supply shocks across U.S. regions, while there are only five EMU countries whose supply shock tend to converge with those of Germany, may be due to the fact that there are more structural economic resemblances amongst U.S. regions than European countries. In other words, despite all their idiosyncrasies, when taken altogether, U.S. regions are a more cohesive economic bloc than European countries. 


\subsection{Policy implications for the EMU}

Can these results shed light on the future of the EMU? Can the United States provide insightful lessons for the European monetary union? Interestingly, Eichengreen (2007) argued that the efforts made by scholars to draw parallels between the EMU and other monetary unions are more likely to mislead than to enlighten, since "where history is useful is not in drawing parallels but in pinpointing differences" (Eichengreen 2007, p.1) and the current underlying framework of the EMU has never been set before. Despite the appropriateness of the argument, one can still draw relevant conclusions for the EMU from the American monetary union, since there are clear resemblances between them: according to the terminology put forward by Bordo and Jonung (1999), they are both national monetary unions, as there is a single monetary authority common to all members of the union, and they are about the same size in population and GDP. Moreover, it is also important to highlight that by the time the monetary union was being built in the U.S., this process of integration was threatened by cultural, economic and institutional differences between north and south.

One of the main results of this inquiry has shown that, with respect to the symmetry of demand shocks, which are more cyclical in the sense that they are mainly driven by policies, there is a clear desynchronisation between a significant group of EMU economies and Germany. For U.S. regions, on the other hand, there is no such clear-cut evidence. The first question one should ask himself is why is this so? According to Bordo (2004), this may hinge on the fact that real integration in the EMU falls short when compared with the experience of the U.S. monetary union ${ }^{27}$. Indeed, in the U.S., even though the fifty states retain fiscal independence, tax revenues can also be raised by the national Government, which uses part of its receipts to redistribute across states. Cyclical disturbances are thereby smoothed by a common fiscal policy set by the federal Government. On the contrary, though the European Commission has created several funds with redistributive functions, which aim precisely to tackle country-specific economic performances, these are still clearly limited. In fact, the annual budget set by the EC only amounts to roughly $1 \%$ of its GDP, which prevents one from even talking about the existence of a common fiscal policy at the European level. Furthermore, it is also important to take into account that a regional negative shock in the United States is largely adjusted by an outflow of workers to more prosperous regions, whereas in Europe labour movements remain rather sluggish, as pointed out in Chapter 2.

I follow this argument very closely when I claim that this difference of results amongst the EMU and the U.S. stems, not only from the fact that European countries are more prone to be hit by asymmetric disturbances in comparison with their American counterparts, but also because they do not

${ }^{27}$ Real integration is meant to denote the integration of goods, capital and labour markets, as well as fiscal harmonisation and synchronisation of shocks and business cycles across members of the monetary union. 
have the required instruments to deal with such idiosyncratic shocks. First, they are increasingly subject to be hit by asymmetric shock because structural differences between them are much more highlighted than amongst U.S. regions. This was shown by the study of the evolution of synchronisation of supply shocks. Second, desynchronisation of demand shocks tends to arise because real integration in Europe was not fully achieved. So, if these structural differences across European countries are coupled with a short integration in the real side, a common monetary policy defined by the European Central Bank cannot be a sufficient mechanism to accommodate specific shocks at the country level: one size cannot fit all. Indeed, asymmetric disturbances will invariantly continue to appear due to structural and permanent differences between countries, while the latter will remain unarmed to tackle them, thus leading to an increasing desynchronisation.

Therefore, given the structural differences amongst European countries, a sustainable and successful European monetary union requires that other policy instruments be at the disposal of member states of the union, so that they can tackle increasingly desynchronised demand shocks. To that extent, the institutionalising of a system of fiscal federalism, as the one which prevails in the United States where fiscal transfers are assigned from the federal Government to deficit states, seems to be an appropriate reform to be undertaken by European leaders. On the one hand, a system of interregional fiscal transfers would allow countries to have an instrument able to stabilise the level of output in response to frequent asymmetric disturbances. On the other, since more fragile countries recently had their ability to conduct counter-cyclical policies constrained, it would overcome the fact that international capital markets may not be the best risk-sharing mechanism within a currency area.

Despite its appropriateness, a solution like this cannot be implemented easily. Indeed, as the creation of a centralised fiscal authority in Europe requires that part of national fiscal policies be delegated to a supranational institution, this implies a large step of political integration that many national Governments within the Eurozone may still not want to take. In the U.S., for example, furthering real and monetary integration was built upon a firm political base set by the Constitution of 1789, whereas political will in Europe seems to have lagged behind. Furthermore, Spolaore (2013) warned that political integration brings about significant costs when it is pushed forward across countries which speak different languages, have different cultures, identities and policy preferences. Hence, the ability of European leaders to come up with a solution that is likely to render this increasing desynchronisation of demand shocks less harmful for the sustainability of the EMU depends largely on the force of political will to push integration forward ${ }^{28}$.

\footnotetext{
${ }^{28}$ The case for a more integrated labour market at the European level could have also been made: if labour movements across European countries do increase, then asymmetric shocks can be automatically tackled with outflows of workers from the negatively hit countries to the positively hit ones. Yet, I believe a solution like this goes far beyond the scope of Economic science, since it also deals with important social and cultural issues that must be taken into proper account.
} 


\section{Conclusion}

This thesis aims to assess whether the hypothesis of endogeneity of OCA criterion regarding the synchronisation of shocks is verified in Europe. The study was also applied to the American monetary union, which served as a standard of comparison.

A three-step econometric methodology was followed. Firstly, I recovered structural demand and supply shocks from the data as suggested by Blanchard and Quah (1989). Secondly, instead of building my analysis upon static correlation coefficients across shocks to the several European countries and U.S. regions, I estimated a spate-space model, whose ability to yield time-varying coefficients allows to have a better approach towards the problem at hand. Demand- and supply-side shocks to the several economies under analysis were, therefore, used as dependent variables of the state-space model, while structural shocks to Germany and to the Mid-East - the chosen benchmark regions for the European and American datasets, respectively - were taken as independent variables. The estimated time-varying coefficients could then be interpreted as dynamic measures of correlation. Lastly, those same time-varying coefficients were regressed in a trend variable, so that the convergence or divergence of shocks amongst the several economies and their benchmark regions could be accurately assessed.

The results showed that, in Europe, the hypothesis of endogeneity could not be unequivocally confirmed. The hypothesis of endogenous demand shocks was rejected in nine out of the nineteen European countries, while the endogeneity of supply shocks was rejected in eight of them. Conversely, the results for the United States were much better. The endogeneity of demand shocks was rejected in three out of eight U.S. regions, whereas the endogeneity of supply shocks was only rejected once.

Other economic and political interpretations were made in the light of the obtained results. For the European countries where the hypothesis of endogenous synchronisation of demand shocks was not rejected, there was a predominance of Krugman's pessimistic view about the effects of higher integration in the correlation of shocks and business cycles: for the nine EMU members where the hypothesis was not rejected, in eight of them there was an increasing desynchronisation of demand shocks with those of Germany. This result can be particularly alarming in a monetary union where prices are sticky, sluggish labour movements cannot work as stabilisation tools, a centralised fiscal policy is absent and the use of sovereign fiscal policy is constrained. Given the inability of EMU member states to tackle asymmetric and country-specific disturbances, this result calls into question the sustainability of the European monetary union as it currently is. An argument in favour of the need for fiscal federalism in Europe was, therefore, made.

A similar result was obtained when studying the evolution of supply shocks across Eurozone economies, since the data suggest that there are only five EMU members whose supply shocks are 
becoming increasingly synchronised with those of Germany. In the United States, on the contrary, out of the seven regions where the hypothesis of endogeneity was not rejected, there was an increasing synchronisation of supply shocks with those of the Mid-East in five of them. Given the fact these supply-side shocks were read as permanent disturbances that affect economically similar regions, these two last results were taken as empirical proof that U.S. regions are a more cohesive economic bloc than European countries.

These results must be read in the light of the econometric methodology followed. It was highlighted, for instance, that the SVAR model which was used to recover structural demand and supply shocks is not free from criticism. Similarly, other schemes to identify the structural shocks could have been used: demand shocks could be interpreted as temporary disturbances to unemployment or industrial production, while supply shocks could be taken as permanent disturbances to the consumer price index. The use of these alternative schemes would also have the advantage to increase the number of observations, since all three aforementioned variables are updated on a monthly basis, whereas data for real GDP and GDP deflator are only given for at least every quarter.

The issue regarding the data must be also taken into account. Firstly, I should mention that the choice of having data spanning the period 1997q1-2015q4 for a dataset of nineteen European countries plus the Euro Area as a whole is entirely mine. I could have had, instead, a smaller sample of countries, but with a larger number of observations. Nevertheless, I strongly believe this research enterprise was enriched by the fact that the hypothesis of endogeneity of synchronisation of shocks was studied, not only in a core of very similar Central Europe economies, but also across very different countries from Southern and Eastern Europe.

These caveats are presented, not only for the sake of transparency, but also because they can lay the groundwork for future research. Indeed, if there is a result one should keep from this work is that the discussion about the endogeneity of OCA criterion regarding synchronisation of shocks in Europe is far from over. There is, in fact, plenty of room for improvement: other schemes for the identification of structural shocks can be used, like the aforementioned ones; the number of observations can be enlarged, thus strengthening the results; the evolution of the dynamic measure of correlation can be assessed with more sophisticated econometric techniques; and other monetary unions, as the Canadian one, who shares with the EMU the existence of some language barriers between their English and French parts, can be used as useful standards of comparison to draw insightful perspectives to a sustainable European monetary union.

Though the way to improve upon this work of mine is left wide-open, I sincerely hope that, for now, it can spark a new sort of thinking about optimum currency area theory. 


\section{References}

(1) Artis, M. (2002), "Reflections on the optimum currency area (OCA) criteria in the light of EMU", Central Bank of Chile - Working Paper n 193

(2) Bayoumi, T. and Eichengreen, B. (1992a), "Shocking Aspects of European Monetary Integration", National Bureau of Economic Research - Working Paper nº 3949

(3) Bayoumi, T. and Eichengreen, B. (1992b), "Is there a conflict between EC enlargement and European monetary unification?", National Bureau of Economic Research - Working Paper n 3950

(4) Bayoumi, T. and Eichengreen, B. (1994), "One money or many? Analyzing the prospects for monetary unification in various parts of the world", Princeton Studies in International Finance $\mathrm{n}^{\mathrm{o}} 76$, International Finance Section - Department of Economics, Princeton University, September

(5) Bayoumi, T. and Eichengreen, B. (1996), "Operationalizing the theory of optimum currency areas", Centre for Economic Policy Research (CEPR) - Discussion Paper n 1484

(6) Bayoumi, T. and Eichengreen, B. (1997), "Ever close to heaven? An optimum-currency-area index for European countries", European Economic Review 41, pp. 761-770

(7) Bayoumi, T. and Masson, P. (1995), "Fiscal flows in the United States and Canada: Lessons for monetary union in Europe", European Economic Review 39, pp. 253-274

(8) Beine, M. and Hecq, A. (1997), "Asymmetric Shocks Inside Future EMU", Journal of Economic Integration 12, $N^{\circ} 2$, pp. 131-140

(9) Blanchard, O. and Quah, D. (1989), "The Dynamic Effects of Aggregate Demand and Supply Disturbances", American Economic Review 79, pp. 655-673

(10) Blanchard, O. and Katz, L. (1992), "Regional Evolutions", Brookings Papers on Economic Activity 1, pp. 1-75

(11) Boone, L. (1997), "Symmetry and Asymmetry of Supply and Demand Shocks in the European Union", Centre D'Études Prospectives et D'Informations Internationales (CEPII) - Working Paper $\mathrm{N}^{\circ}$ 1997-03, March 1997

(12) Bordo, M. (2004), "The Untied States as a monetary union and the Euro: A historical perspective", Cato Journal 24, pp. 163-170

(13) Bordo, M. and Jonung, L. (1999), "The Future of EMU: What Does the History of Monetary Unions Tell Us?", National Bureau of Economic Research - Working Paper $\mathrm{n}^{\circ} 7365$ 
(14) Bordo, M., Jonung, L. and Markiewicz, A. (2013), "A Fiscal Union for the Euro: Some Lessons from History", CESifo Economic Studies 59, pp. 449-488

(15) Chamie, N., DeSerres, A. and Lalonde, R. (1994), "Optimum currency areas and shock asymmetry: A comparison of Europe and the United States", Bank of Canada - Working Paper 94-1

(16) Decressin, J. and Fatás, A. (1995), "Regional labour market dynamics in Europe", European Economic Review 39, pp. 1627-1655

(17) Dées, S. and Zorell, N. (2011), "Business cycle synchronisation: Disentangling trade and financial linkages", European Central Bank - Working Paper Series nº 1322/April 2011

(18) De Grauwe, P. (1996), "Monetary union and convergence economics", European Economic Review 40, pp. 1091-1101

(19) De Grauwe, P. (2013), "Design Failures in the Eurozone: Can they be fixed?", LSE "Europe in Question" Discussion Paper Series, LEQS Paper No 57/2013, February 2013

(20) De Grauwe, P. (2016), "Economics of Monetary Unions", Oxford University Press, Eleventh Edition

(21) Eichengreen, B., Obstfeld, M., Spaventa, L. (1990), "One Money for Europe? Lessons from the US Currency Union", Economic Policy 5, pp.117-187

(22) Eichengreen, B. (1991), "Is Europe an optimum currency area?", National Bureau of Economic Research - Working Paper no 3579

(23) Eichengreen, B. (2007), "Sui Generis EMU", National Bureau of Economic Research Working Paper no 13740

(24) European Commission (1990), "One market, one money - An evaluation of the potential benefits and costs of forming an economic and monetary union", European Economy $n^{\circ} 44$

(25) Fatás, A. (1997), "EMU: Countries or regions? Lessons from the EMS experience", European Economic Review 41, pp. 743-751

(26) Frankel, J. and Rose, A. (1996), "The endogeneity of the optimum currency area criteria", National Bureau of Economic Research - Working Paper n ${ }^{\circ} 5700$

(27) Frankel, J. and Rose, A. (1997), "Is EMU more justifiable ex-post than ex-ante?", European Economic Review 41, pp. 753-760

(28) Funke, M. (1997), "The Nature of Shocks in Europe and in Germany", Economica 64, pp. 461469 
(29) Gáková, Z. and Dijkstra, L. (2008), "Labour mobility between the regions of the EU-27 and a comparison with the USA", European Commission - Directorate-General for Regional Policy, Regional Focus $n^{\circ} 02 / 2008$

(30) Krugman, P. (1993), "Lessons of Massachusetts for EMU", in F. Giavazzi and F. Torres, "The Transition to Economic and Monetary Union in Europe", New York: Cambridge University Press, 1993, pp. 241-261

(31) Lane, P. (2013), "Capital flows in the Euro Area", European Commission - DirectorateGeneral for Economic and Financial Affairs, Economic Papers 497, April 2013

(32) Lippi, M. and Reichlin, L. (1993), "The Dynamic Effects of Aggregate Demand and Supply Disturbances: Comment", American Economic Review 83, pp. 644-652

(33) Lucas, Robert (1976), "Econometric Policy Evaluation: A Critique" in Brunner, K. and Meltzer, A. "The Philips Curve and Labour Markets", Carnegie-Rochester Conference Series on Public Policy, American Elsevier, 1976, pp.19-46

(34) Kenen, Peter (1969), "The theory of optimum currency areas: An eclectic view" in Robert A. Mundell and Alexander K. Swoboda, "Monetary problems of the international economy", Chicago: University of Chicago Press, 1969, pp. 41-60

(35) McKinon, Ronald (1963), "Optimum currency areas", American Economic Review 53, pp. 717-725

(36) Mundell, Robert A. (1961), "A theory of optimum currency areas", American Economic Review 51, pp. 657-665

(37) Sala-i-Martin, X. and Sachs, J. (1991), "Fiscal Federalism and Optimum Currency Areas: Evidence for Europe from the United States", National Bureau of Economic Research - Working Paper $n^{\circ}$ 3855

(38) Spolaore, E. (2013), "What is European Integration Really About? A Political Guide for Economists", Journal of Economic Perspectives 27(3), pp. 215-244

(39) Verhoef, B. (2003), "The (A)symmetry of Shocks in the EMU", DNB Staff Reports $N^{\circ}$ 106/2003

(40) Weber, A. (1990), "EMU and asymmetries and adjustment problems in the EMS: Some empirical evidence", Centre for Economic Policy Research (CEPR) - Discussion Paper no 448

(41) Wynne, M. and Koo, J. (2000), "Business Cycles under Monetary Union: A Comparison of the EU and the US", Economica 67, pp. 347-374 